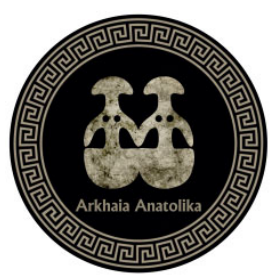

Arkhaia Anatolika

Anadolu Arkeolojisi Araştırmaları Dergisi

The Journal of Anatolian Archaeological Studies

Volume 4 (2021)

\title{
Menderes Magnesiası Artemis Kutsal Alanı Güney Stoa'da Bulunan Doğu Sigillata B Grubu Seramikleri
}

\author{
Eastern Sigillata B from the South Stoa of the Sanctuary of Artemis at \\ Magnesia on the Meander
}

\section{Mevlüt ELIÜŞÜK}

(iD)https:/ / orcid.org/0000-0002-8888-9689

Geliş Tarihi: 30.11.2020 | Kabul Tarihi: 14.01.2021 | Online Yayın Tarihi: 18.01.2021

Makale Künyesi: Eliüşük, M. (2021). Menderes Magnesiası Artemis Kutsal Alanı Güney Stoa'da Bulunan Doğu Sigillata B Grubu Seramikleri. Arkhaia Anatolika, 4, 1540. DOI: 10.32949/Arkhaia.2021.25
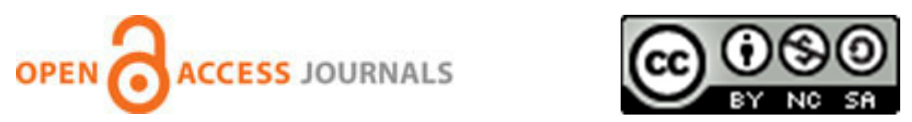

Arkhaia Anatolika, Anadolu Arkeolojisi Araştırmaları Dergisi "Açık Erişimli" (Open Access) bir dergidir. Kullanıcılar, dergide yayınlanan makalelerin tamamin tam metin olarak okuyabilir, indirebilir, makalelerin çıktısını alabilir ve kaynak göstermek suretiyle bilimsel çalışmalarında bu makalelerden faydalanabilir. Bunun için yayıncıdan ve yazar(lar)dan izin almasına gerek yoktur.

Dergide yayınlanan makalelerin bilimsel ve hukuki sorumluluğu tamamen yazar(lar)ına aittir.

Arkhaia Anatolika, The Journal of Anatolian Archaeological Studies follows Open Access as a publishing model. This model provides immediate, worldwide, barrier-free access to the full text of research articles without requiring a subscription to the articles published in this journal. Published material is freely available to all interested online readers.

The scientific and legal propriety of the articles published in the journal belongs exclusively to the author(s). 


\title{
Menderes Magnesiası Artemis Kutsal Alanı Güney Stoa'da Bulunan Doğu Sigillata B Grubu Seramikleri
}

\author{
Eastern Sigillata B from the South Stoa of the Sanctuary of Artemis at Magnesia on \\ the Meander
}

Mevlüt ELİ̈ŞÜK*

Öz

Menderes Magnesiası antik kentinde, Hermogenes'in başyapıtı olan Artemis Tapınağı'nın güneyini sınırlandıran stoa ile bu stoanın gerisindeki mekanlarda yapılan kazı çalışmalarında ele geçen en yoğun buluntu grubunu, geniş bir zaman dilimine yayılan seramikler oluşturmaktadır. Bu seramik grupları içerisinde, 161 parça ile temsil edilen Doğu Sigillata grubuna ait örneklerden 160'ının Doğu Sigillata B grubunda yer alması dikkat çekicidir. Bu çalışmada, Menderes Magnesiası Güney Stoa'da bulunan ve form özellikleri tespit edilebilen Doğu Sigillata B grubuna ait 29 adet seramik ele alınarak, bunların bilim dünyasına tanıtılması amaçlanmıştır. Kentte yoğun olarak çalışılan mimari sektörün yanında seramik araştırmalarına da ağırlık verilerek, üretim, dağıtım ve bölgesel ilişkiler gibi konuları anlamlandırmaya yardımcı olmak hedeflenmektedir.

Güney Stoa'da bulunan seramikler DSB-I ve DSB-II olmak üzere iki alt başlıkta incelenmiştir. Analoji çalışmaları sonucunda, DSB-I'e giren beş form tespit edilmiştir. DSB-I başlığı altında değerlendirilen Hayes Form 22, MÖ 1. yüzyılın sonu ile MS 1. yüzyılın ilk çeyreğine aittir ve en erken örnek olarak belirlenmiştir. Diğer DSB I örnekleri olan "Hayes Form 7, 19, 26 ve 29" ise MS 1. yüzyılın ilk yarısı ve ortalarına tarihlendirilmiştir. DSB-II başlı̆̆ 1 altında değerlendirilen grupta ise tabak, kase ve çift kulplu kaseden oluşan yedi farklı form bulunmaktadır. Bu grubun en erken örneği olan Hayes Form 58, MS 1. yüzyılın ikinci yarısına tarihlenirken, grubun en geç örneklerini oluşturan Hayes Form 60 ve 70'in geç versiyonları, MS 2. yüzyılın ikinci yarısı ile MS 3. yüzyılın birinci yarısına tarihlendirilmiştir. Mimari bezeme özelliklerine göre Erken İmparatorluk Dönemi'ne tarihlenen Güney Stoa'da bulunan DSB örneklerinin değerlendirilmesi sonucunda, yapının mimarisi ile buluntularının uyumlu olduğu anlaşılmıştır. Özellikle Artemis Kutsal Alanı Güney Stoa ile kentin kazısı yapılan diğer alanlarında yoğun olarak bulunan DSB örnekleri ışığında, Magnesia'nın DSB üretim merkezleri olarak önerilen Tralleis ve Ephesos gibi kentlerle ilişkilerinin güçlü olduğu ve DSB grubu çanak çömleklerin üretiminin en azından MS 3. yüzyılın ortalarına kadar devam ettiği sonucuna ulaşılmıştır.

Anahtar Kelimeler: Menderes Magnesiası, Sigillata, Doğu Sigillata B, DSB, Güney Stoa, Artemis Kutsal Alanı

\section{Abstract}

Potteries, dating from the 5th century BC to the 15-16 centuries AD were found during the excavations in the South Stoa of the Sanctuary of Artemis at Magnesia on the Meander. Among these potteries, the Eastern Sigillata ware constitutes the largest group. 161 pieces of the pottery found in the South Stoa belong to the

\footnotetext{
* Dr. Öğr. Üyesi Mevlüt Eliüşük, Karabük Üniversitesi, Edebiyat Fakültesi, Arkeoloji Bölümü, Demir Çelik Kampüsü, Karabük/TR. E-mail: mevluteliusuk@karabuk.edu.tr. / Orcid iD: 0000-0002-8888-9689
}

Makaleye konu olan malzemeleri çalışmama imkan tanıyan değerli hocam Prof. Dr. Orhan Bingöl'e yardımlarından dolayı çok teşekkür eder, şükranlarımı sunarım. 
Eastern Sigillata, and 160 pieces of them belong to the Eastern Sigillata B. In this study, 29 potteries belonging to the East Sigillata B found in the South Stoa are discussed.

The pottery found in the South Stoa has been examined under two subtitles as ESB-I and ESB-II. As a result of the analogy, five forms included in ESB-I was determined. Hayes Form 22, evaluated in the ESB-I group, belongs to the end of the 1st century $\mathrm{BC}$ and the first quarter of the 1st century $\mathrm{AD}$ and was identified as the earliest example. Other ESB-I examples such as "Hayes Form 7, 19, 26 and 29" are dated to the first half and middle of the 1st century AD. In the group evaluated in ESB-II, there are seven different forms consisting of plates, bowls and double handled bowls. The earliest example of this group, Hayes Form 58, was dated to the second half of the 1st century AD, while the late versions of Hayes Form 60 and 70, the latest examples of this group, were dated to the second half of the 2nd century AD and the first half of the 3rd century AD. As a result of the evaluation of the ESB found in the South Stoa dated to the Early Imperial Period according to the architectural decoration features, it was understood that the architecture of the building and its findings were compatible. Especially in the light of ESB, which are densely found in the South Stoa of the Sanctuary of Artemis and other areas of the city, it was concluded that Magnesia on the Meander had strong relations with cities such as Tralleis and Ephesos, which were proposed as ESB production centers, and that the production of ESB continued at least until the middle of the 3rd century AD.

Keywords: Magnesia on the Meander, Sigillata, Eastern Sigillata B, ESB, Southern Stoa, Artemis Sanctuary

Menderes Magnesiası antik kenti, Aydın İli, Germencik İlçesi, Ortaklar Mahallesi, Tekinköy sınırları içerisindedir. Günümüzde Ortaklar-Söke karayolu ile doğu kenarından ikiye bölünmüş olan Artemis Kutsal Alanı'nın büyük çoğunluğunu oluşturan mekanların kalıntıları, karayolunun batısında bütüncüllüğünü korumaktadır. Doğu, kuzey ve güneyinden stoalar ile çevrili olan kutsal alanın doğusunda Artemis Tapınağı, tapınağın batısında Artemis Sunağı, kurban alanı ve toplantı alanı yer alır. Kutsal alanın ${ }^{1}$ kuzeyini ve güneyini sınırlandıran stoalarının gerisinde mekanlar vardır. Bunlar, kuzeyde Latrina ve Kütüphane, güneyde ise Triclinium, Heroon ve İmparatorlar Salonu'dur. Kutsal alan, batıdaki propylon ile agoraya bağlanmaktadır.

Artemis Kutsal Alanı Güney Stoa'da 2000-2001, 2005-2006, 2009, 2012, 2014, 2016, 2018-2020 yılları olmak üzere aralıklarla kazı çalışmaları yapılmıştır. Çalışmamız kapsamında Güney Stoa ile dış mekan yapıları olarak adlandırılan Triclinium, Flaviuslar Salonu $^{2}$ (İmparatorlar Salonu) ile onun her iki yanındaki heroonlardan ve ara mekanlardan ele geçen seramik buluntuları, bütün oluşturmasından dolayı birlikte değerlendirilmiştir³. Öncelikle çalışmamızın ilk aşamasında alanda bulunan tüm malzeme detaylı olarak incelenmiş ve sınıflandırılmıştır. Bu değerlendirme kapsamında, seramik parçalarından en erken örneğin MÖ 5. yüzyıla ait kase, en geç örneklerin ise MS 15.-16. yüzyıla ait Mavi-Beyaz seramik parçalarından oluştuğu tespit edilmiştir (fig. 1). Güney Stoa malzemesinin genel kontekst özellikleri değerlendirildiğinde, nitelikli seramik örnekleri içerisinde en yoğun buluntu grubunu Doğu Sigillata grubu seramikler oluşturmaktadır.

Terra Sigillata terimi ilk olarak H. Dragendorff ${ }^{4}$ tarafindan Arretine'de bulunan kırmızı astarlı, baskılı, kaliteli kaplar için kullanılmıştır. Bu kaplara benzer astar yapısına sahip kapların Roma İmparatorluğu'nun doğusundaki çeşitli merkezlerde bulunmaları ve üretildiği düşünülen yer isimleri ile anılmalar15, terminolojik problemleri meydana getirmiştir. Üretim yerleri kesin olmayan farklı özelliklerdeki kırmızı astarlı seramikler için K. M. Kenyon ${ }^{6} 1957^{\prime}$ de yaptığı çalışma ile alfabetik isimlendirme önerisi getirmiş ve

\footnotetext{
${ }^{1}$ Kutsal alandaki yapılar için bk. Bingöl 2020, 44-86.

2 Yapının genel özellikleri için bk. Bingöl 2020, 81-82.

${ }^{3}$ Güney Stoa dış mekan yapıları ve buluntuları için bk. Bingöl 2020, 78-83.

4 Dragendorff 1895, 19.

5 Zahn 1904, 447-448; Y1ld1z 2019a, 109.

6 Kenyon 1957, 282.
} 
günümüzde de kabul gören bu isimlendirmeye göre Doğu Sigillatalar $A, B, C$ ve $D^{7}$ olmak üzere dört farklı grupta anılmaya başlamıştır ${ }^{8}$. Konumuzu oluşturan Doğu Sigillata B grubu seramikler ilk başlarda Plinius'un tanımladığı vasa samia (Plin. nat. XXXV, 160-161) olduğu düşünülmüss ve bu grup Samian Seramiğ ${ }^{9}{ }^{9}$ olarak isimlendirilmiştir. Kapları tanımlamada yetersiz kalan bu isimlendirme, Kenyon'un önerisiyle yerini Doğu Sigillata B'ye bırakmıştır ${ }^{10}$. DSB grubu seramikleri kendi içinde farklı hamur, astar ve yapısal özellikleri tanımlamak için önceleri H. S. Robinson' un ${ }^{11}$ isimlendirmesiyle Samian A ve Samian B; daha sonra P. Hellström'ün ${ }^{12}$ önerisiyle DSB-I (=Samian B) ve DSB-II (=Samian A) olarak ayrılmıştır. $1985^{\prime}$ te J. W. Hayes' in ${ }^{13}$ çeşitli merkezlerde bulunan seramikler ile yaptığı çalışma DSB'ler için tipolojik ve kronolojik olarak en kapsamlı kaynağı oluşturur. Günümüzde de sıklıkla kullanılan geniş çaplı tipolojiye rağmen, MÖ 1. yüzyılın sonlarından başlayıp, MS 2. yüzyılın ortalarında son bulan DSB kronolojisine karşın, son araştırmalar en azından bölgesel olarak DSB grubunun MS 3. yüzyılın ortalarına kadar üretimde ve dağıtımda olduğunu kanitlayarak, kronolojiyi genişletirir. DSB'ler için çeşitli üretim merkezleri ileri sürülse de son dönemlerde genel kanı, bu seramiklerin Tralleis'teki ${ }^{15}$ atölyelerde üretildiğidir.

Doğu Sigillata grupları arasında tipolojik, kronolojik, üretim merkezi ve seramiklerin bölgesel dağılımı gibi konular bakımından en çok sorunsalı bulunan grubu DSB'ler oluşturmaktadır. Bu çalışma ile Artemis Kutsal Alanı Güney Stoa'da sayısal olarak en yoğun buluntu topluluğunu oluşturan DSB'lerin bilim dünyasına tanıtılması amaçlanmıştır. Kentte yoğun olarak çalışılan mimari sektörün yanında seramik araştırmalarına da ağırlık verilerek, üretim, dağıtım ve bölgesel ilişkiler gibi konuları anlamlandırmaya yardımcı olmak hedeflenmektedir.

Artemis Kutsal Alanı Güney Stoa'da ele geçen 161 adet Doğu Sigillatadan yalnız bir

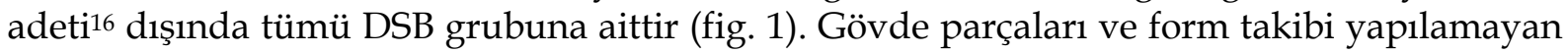
küçük boyutlu parçalar çalışma kapsamı dışında bırakılmıştır. Ele alınan 29 parça seramik Hayes'in tipolojisine bağlı kalınarak gruplandırılmış; yalnız bir grup Hayes'in tipolojisi dışında kaldığı için Mitsopoulos-Leon'un ayrımına başvurulmuştur. Kentte stratigrafik çalışmayı engelleyen unsurların olması; özellikle 20. yüzyılın başlarında yapılan kazılar ile toprağın katmanlarının karıştırılmış olması, malzemenin tarihlendirilmesi için analoji yolunun kullanılmasını gerekli kılmıştır.

Menderes Magnesiası Artemis Kutsal Alanı Güney Stoa'da bulunan DSB'ler, DSB-I ve DSB-II olmak üzere iki alt grupta değerlendirilmiştir.

\section{DSB-I}

Güney Stoa'da bulunan 7 adet seramik, DSB-I grubu içerisinde değerlendirilerek, Hayes Form 7, 19, 22, 26 ve 29 olmak üzere 5 farklı forma ayrılmıştır. Form 7 ve 19 tabak; Form 22, 26 ve 29 kasedir. Tümünün kili katkısız olup Munsell17 renk kataloğuna göre hamur rengi 2.5YR 6/8, astar rengi ise 2.5YR 4/8'e karşıllik gelmektedir.

\footnotetext{
7 Doğu Sigillata D, Rosenthal'ın önerisiyle terminolojiye eklenmiştir bk. Rosenthal 1978, 18.

8 Yildız 2016, 255; Tekocak 2019, 90; Yıldız 2019a, 109; Yıldız 2019b, 248.

9 Zahn 1904, 447-448.

10 Makalenin geri kalan bölümünde Doğu Sigillata B yerine DSB kısaltması kullanılacaktır.

11 Robinson 1959, 12.

12 Hellström 1965, 28-29.

13 Hayes $1985,49-70$.

14 Hayes 2008, 39-40; Ladstätter 2008, 111; Bes 2017, 243.

15 Takaoğlu 2006, 263-265.

${ }^{16}$ Güney Stoa' da bulunan 161 adet sigillatadan yalnız bir adeti Doğu Sigillata C grubu Hayes Form L 26'ya aittir.

17 Munsell 2013.
} 




Figür 1: Güney Stoa' da bulunan Kırmızı Astarlı Seramiklerin istatistiğì18

\section{Tabak}

Hayes Form 7: (Lev. 1, Kat. No. 1-2)

Çıkıntı yapan dudak ve gövdeye geçişte dirsek profili oluşturan dikey kenar, eğimli kısa, sığ gövde, alçak halka kaide özelliği gösteren tabak formundan Güney Stoa'da 2 parça ele geçmiştir. Çift daldırma olarak uygulanan kalın ve parlak astarı olan tabaklardan kat. no. 1 'de fırça izi görülmektedir. Hayes dudak ve kenar-gövde birleşiminde dirsek yapan dik kenarlı DSB-I tabaklarını Form 6, 7 ve $8^{19}$ olarak sınıflandırmıştır. Kenar-gövde parçası olarak ele geçen kat. no. 1'in dirsek altında ve iç yüzün dik kenarında oldukça ince, çift sıra yiv yer alır. Aşağı dönük dudak çıkıntısı ve yuvarlak hatlı dirsek çıkıntısına sahip olan parçanın iç yüzünde kenardan gövdeye geçişte belirgin yiv bulunur. Kat. no. 2 dirsekten kırılmış kaidegövde parçasıdır ve yuvarlak hatlı dirsek profili, alttan bir ince ve bir de derin-kalın yiv ile belirginleştirilmiştir. Alçak halka kaidenin oturma düzleminde ve kaide içinde tabana geçişte birer yiv görülmektedir. Tabağın iç yüzünde tabana geçişte derin yiv bulunur. Tondonun merkezinde kırık olmasına rağmen mühür çerçevesi ve mührü çevreleyen çift sıra yiv ile onları çevreleyen tek sıra yiv yer almaktadır. Bu özellikleri ve çapları dikkate alındığında, iki parça da Hayes'in Form 7 sinıflandırmasına uymaktadır. Artemis Kutsal Alanı Güney Stoa'da ele geçen tabakların benzerleri Ephesos'ta Bazilika20, Tetraganos Agorası Güney $\mathrm{Kap}_{11}{ }^{21}$ ve Devlet Agorası Kuyu ${ }^{22}$ buluntuları içerisinde, Aizonai23, Labraunda ${ }^{24}$, Patara ${ }^{25}$, Andriake $^{26}$ ve Berenice'de ${ }^{27}$ görülür. Form 7'yi Hayes, MS 1. yüzyılın ikinci çeyreğine

18 Kullanılan kısaltmalar: DSB: Doğu Sigillata B, DSC: Doğu Sigillata C, AKAS: Afrika Kırmızı Astarlı Seramikleri, FKAS: Foça Kırmızı Astarlı Seramikleri.

19 Hayes 1985, 54, lev. XI, 15-16 (form 6); Hayes 1985, 54-55, lev. XI, 17-18 (form 7); Hayes 1985, 55, lev. XI, 19 (form 8).

20 Mitsopoulos-Leon 1991, 100-101, lev. 120-130, H 23-54.

21 Gassner 1997, 130, lev. 42, 492-494.

22 Meriç 2002, 49, 57, lev. 21, K 188-192.

23 Ateş 2002, 326-328, fig. 2, 2-5.

24 Hellström 1965, 33, lev. 35, 212-213.

25 Uygun 2011, 49, lev. 24, 346-357.

26 Özdilek 2018, 643, fig. 2, kat. no. T. 2.

27 Kenrick 1985, 247, fig. 45, B 344. 
tarihlendirmiştir. V. Gassner ${ }^{28}$ formun MS 1. yüzyılın ilk çeyreğinde Ephesos Tetraganos Agora buluntuları içinde yoğun olarak bulunduğunu belirtmektedir. Bu çerçevede benzerleri dikkate alındığında, Form 7'yi MS 1. yüzyılın ilk yarısına tarihlendirmek yanlış olmayacaktır.

Hayes Form 19: (Lev. 1, Kat. No. 3)

İçe dönük kenar, konik sı̆̆ gövde, merkeze doğru yükseltilen düz dip özelliği gösteren tabak formudur. Güney Stoa'da tek kenar parçası olarak temsil edilen form, 2.5YR 6/8 hamur, 2.5YR 4/8 kalın, parlak astara sahiptir. İçe dönük kenarın iç yüzünde yiv bulunur. Oldukça sade olarak tasarlanmış bu tip tabakları Hayes, Form 1929 olarak sınıflandırmıştır. Form 60'ın ${ }^{30}$ DSB-I'deki karşıllı̆̆ 1 olan Form 19'un benzerleri Ephesos ${ }^{31}$, Tralleis $^{32}$, Labraunda ${ }^{33}$ ve Patara' da ${ }^{34}$ bulunur. Bu örnekler doğrultusunda, Artemis Kutsal Alanı Güney Stoa'da ele geçen Form 19, MS 1. yüzyılın ortalarına tarihlendirilmiştir.

\section{Kase}

Hayes Form 22: (Lev. 1, Kat. No. 4)

Dışa çekik kenar, kıvrılarak yükseltilmiş dikey dudak, alt gövdeden keskin açıyla kaideye yönelen dikey, derin gövdeli kase formudur. Kenarın iç yüzünde ince yiv ile dudak belirginleştirilmiştir. Hayes'in Form $22^{35}$ olarak sınıflandırdığı kaseler oldukça nadir görülmektedir. Kenar ve gövdenin ince cidarına karşın kalın-ağır kaidenin olması bu tip kaselerin parçalara ayrılmasını kolaylaştırabileceğinden, bu durum kaselerin tespitini zorlaştırmış olabilir. Artemis Kutsal Alanı Güney Stoa' da Form 22'ye ait kenar-gövde parçası olarak tek bir örnek bulunmuştur. Keskin dönüşle kaideye yönelen alt gövdeden kırılmış olan parça, kalın parlak astarlıdır. Bu forma benzer düz kenarlı, içbükey gövdeli Form $21^{36}$ ile dişa çıkıntılı kenar, "S" profilli gövde özelliği gösteren Form 2337 örneklerinden Form 22'nin kaide yapısı hakkında fikir sahibi olabilmek mümkündür. Kat. no. 4'e tek benzer örnek Korinth'te ${ }^{38}$ bulunmaktadır. Ayrıca Patara' da ${ }^{39}$ da Form 22 olmasına rağmen benzerlik sağlamamaktadır. Tarihlendirmede Hayes'in Augustus Dönemi'ni önerdiği Form 22, DSBI'in erken formlarından olmalıdır. Bu nedenle kat. no. 4'ü MÖ 1. yüzyılın sonu ile MS 1. yüzyılın ilk çeyreği arasına tarihlendirmek yerinde olacaktır.

Hayes Form 26: (Lev. 1, Kat. No. 5)

Kademeli yükselen gövde, girintiyle gövdeye birleştirilen ağır halka kaide özelliği gösteren kase formudur. Menderes Magnesiası Güney Stoa'da bulunan kaide parçası, $3 \mathrm{~cm}$ kaide çapıyla oldukça küçük boyuttadır. Kalıp yapımı olan kaidenin dışı girintili çıkıntılı olacak şekilde kademelendirilmiştir. Kaidenin oturma düzleminde yiv, tondonun merkezinde mühür ve mührü çevreleyen çift sıra yiv bulunur. Ayrıca tondodan gövdeye geçiş yiv ile vurgulanmıştır. Mühür dikdörtgen çerçevenin içine yerleştirilmiş C.SN harflerinden oluşmaktadır. Bu damga DSB grubunun kurucusu kabul edilen İtalyan

28 Gassner 1997, 127.

${ }^{29}$ Hayes 1985, 57, lev. XII, 13-14.

30 Hayes 1985, 64, lev. XIV, 5-8.

31 Beyll 1993, 26, lev. 3, 40; Meriç 2002, 51, lev. 22, K 219-220.

32 Erol 2004, 37, lev. 13, çiz. 66; Civelek 2010, 175, lev. 1, fig. 5, 1.

33 Hellström 1965, 33, lev. 35, 217.

34 Uygun 2011, 53-54, lev. 25, 373-377.

35 Hayes 1985, 57, lev. XII, 16-17.

36 Hayes 1985, 57, lev. XII, 15.

37 Hayes 1985, 57-58, lev. XII, 18.

38 Hayes 1973, 454, lev. 86, 141.

39 Uygun 2011, 55, lev. 26, 381. 
çömlekçi C.Sentius ile ilişkilidir"40. C.Sentius ${ }^{41}$ damgaları "C.Sent; CSE; C.SE; C.SEN; C.SN" olarak karşımıza çıkar ${ }^{42}$. Eserde görülen damganın benzeri Aizanoi'da43 aynı form kasenin tondosunda görülmektedir. Parçanın profil özellikleri ve ölçüleri dikkate alındığında, Hayes'in Form $26^{44}$ sinıflandırmasına yerleştirmek yerinde olacaktır. Ephesos Bazilikası4, Patara $^{46}$ ve Atina Agorası'nda47 benzerleri olan kat. no. 5, analoji yardımıyla MS 1. yüzyılın ilk yarısına tarihlendirilmiştir.

Hayes Form 29: (Lev. 2, Kat. No. 6-7)

Yarımküre gövdeli kase formudur. Güney Stoa'da, yuvarlak veya sivri uçla sonlanan dudak, hafif dişbükey gövdeye sahip iki adet kenar parçası ele geçmiştir. Kat. no. 6'nın iç ve dış yüzü düz bırakılmışken, kat. no. 7'nin dış yüzü kenarının hemen altında oldukça sığ çift sıra yiv, iç yüzü ise nispeten daha derin tek sıra yiv ile işlenmiştir. Hayes' in Form $29^{48}$ olarak sınıflandırdığ 1 bu tip kaseler yaygın olarak görülmektedir. Ephesos ${ }^{49}$, Metropolis ${ }^{50}$, Aizonai ${ }^{51}$, Labraunda ${ }^{52}$, Assos ${ }^{53}$, Patara ${ }^{54}$ ve Knossos'ta ${ }^{55}$ tespit edilen formun benzerleri Menderes Magnesiası Gymnasiumu'nda ${ }^{56}$ da görülmektedir. Bu örnekler doğrultusunda, Güney Stoa' da bulunan kat. no. 6 ve 7, MS 1. yüzyılın ilk yarısına tarihlendirilmiştir.

\section{DSB-II}

Güney Stoa'da bulunan 22 adet seramik DSB-II grubu içerisinde değerlendirilerek Hayes Form 57, 58, 60, 70, 71, 80 ve Mitsopoulos-Leon H 144 olmak üzere 7 farklı forma ayrılmıştır. Form 57, 58, 60 ve 80 tabak; Form 70 ve 71 kase; Mitsopoulos-Leon H 144 ise çift kulplu kasedir. Killerinde az veya yoğun mika, az kireç katkısı bulunan parçaların Munsell ${ }^{57}$ renk kataloğuna göre hamur rengi 2.5YR 6/8; 5YR 6/4, astar rengi ise $2.5 \mathrm{YR} 4 / 8,5 / 8$; $10 \mathrm{R}$ 4/8, 5/8'e karşıllı gelmektedir.

\section{Tabak}

Hayes Form 57: (Lev. 2, Kat. No. 8-9)

Çıkıntı yapan dudak, gövdeye geçişte dirsek profili oluşturan dikey kenar, eğimli kısa, sığ gövde, alçak halka kaide özelliği gösteren tabak formudur. Güney Stoa'da 2 parça olarak ele geçen form, Hayes' in tipolojisinde Form 5758 olarak sınıflandırılmıştır. DSB-I'deki Hayes Form 4-8' den ${ }^{59}$ türemiş olan Form 57, öncüllerine kıyasla oldukça küçük boyutludur.

\footnotetext{
40 Hayes 1985, 51. C. Sentius ile ilişkili mühürler için bk. Zahn 1904, 437, 445; Zabehlicky-Scheffenegger 2003, $117-$ 119, lev. LXXV-LXXX; Hayes 2008, 145, lev. 8, 234; Bes 2017, 243, 256, fig. 11 a.

41 C. Sentius atölyesinin üretim ve ticareti için bk. Zabehlicky-Scheffenegger 2003, 117-119.

42 Bes 2017, 256, fig. 11a.

43 Ateş 2003, 185-186, lev. 62, 351.

${ }^{44}$ Hayes 1985, 58, lev. XII, 22.

45 Mitsopoulos-Leon 1991, 103, lev. 146, H 113.

46 Uygun 2011, 58, lev. 27, 402-404.

47 Hayes 2008, 148, fig. 10, 268-269.

48 Hayes 1985, 59, lev. XII, 26-27.

49 Beyll 1993, 22, lev. 1, 9; Gassner 1997, 131, lev. 42, 502-503; Meriç 2002, 51-52, lev. 23, K 223-230.

50 Güngör 2005, 45-46, lev. 21, 103-106.

51 Ateş 2002, 329-332, fig. 3, 18-19.

52 Hellström 1965, 33, lev. 35, 228-229.

53 Zelle 1997, 42-43, fig. 7, 38-40.

54 Uygun 2011, 56-57, lev. 26, 387-389.

55 Sackett 1992, 199, lev. 143, 19.

56 Vapur 2001, 14-15, çiz. 1, 2.

57 Munsell 2013.

58 Hayes 1985, 63, lev. XIV, 2.

${ }^{59}$ Hayes 1985, 53-55, 63, lev. XI, 12-19, lev. XIV, 2.
} 
Tama yakın profil takibi yapılabilen, $7 \mathrm{~cm}$ ağız çapıyla oldukça küçük boyutlu olan kat. no. $8^{\prime}$ in dış yüzünde, dirseğin üzerinde bir, altında oldukça ince yapılmış iki yiv; iç yüzünde ise dik kenarda ve tabana geçişte birer adet yiv bulunmaktadır. Dirsek profilinin hemen üzerinden kırılmış olarak ele geçen kat. no. 9'un dirsek profilinin altında bir ince ve bir de derin-kalın yiv ile iç yüzünde tabana geçişte ince bir yiv yer almaktadır. Ephesos Devlet Agorası Kuyu ${ }^{60}$ buluntular1, Vedius Gymnasiumu ${ }^{61}$ ile Patara ${ }^{62}$ ve Knossos' ta $^{63}$ benzerleri bulunan form, MS 1. yüzyılın ikinci yarısı ile MS 2. yüzyılın ilk çeyreğine tarihlendirilmiştir.

Hayes Form 58: (Lev. 2-3, Kat. No. 10-11)

Dikey kenar, eğimli konik gövde, merkeze eğimli inen tondo ve alçak halka kaide özelliği gösteren tabak formudur. Hayes tarafından Form 5864 olarak sinıflandırılan tabakların genellikle dudak kenarı ve çıkıntı yapan kenar-gövde birleşimi alttan yiv ile belirginleştirilmiş rulet bezemelidir. Tabakların erken örneklerinde kenar cidarı daha ince olabilmekle beraber geç örneklerde kenarda görülen rulet bezeme özenini yitirmiş durumda görülebilmektedir ${ }^{65}$. Güney Stoa' da bu forma ait tam profil veren iki parça ele geçmiştir. Kat. no. 10'un ince cidarlı kenar yapısı ve kalın uygulanmış parlak astarı bu formun erken örneklerinden olduğunu göstermektedir. Kat. no. 11'in ise kenar cidarı daha kalın, rulet bezemesi ise özensizdir. Her iki örneğin de tondo merkezi korunmamakla birlikte muhtemel olabilecek palmet, yıldız vs. mührünü çevreleyen iki sıra yiv görülebilmektedir. Oldukça yaygin olan formun benzerleri Ephesos'ta farkl1 alanlarda ${ }^{66}$, Tralleis ${ }^{67}$, Iasos ${ }^{68}$, Labraunda ${ }^{69}$,

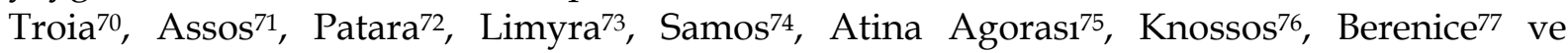
Stobi'de ${ }^{78}$ görülmektedir. Ayrıca Menderes Magnesiası Gymnasiumu ${ }^{79}$ ve Theatronu'nda ${ }^{80}$ da benzerlerine rastlanan kat. no. 10, MS 1. yüzyılın ikinci yarısına, kat. no. 11 ise MS 75-125 yılları arasına tarihlendirilmiştir.

Hayes Form 60: (Lev. 3-4, Kat. No. 12-17)

Dik ya da içe dönük kenar, eğimli gövde ve düz dip özelliği gösteren tabak formudur. Hayes'in Form $60^{81}$ olarak sınıflandırdığ tabaklardan içte ve dişta iki yiv ile kenarın gövdeden ayrıldığı, üçgen görünümlü kenara sahip erken örnekler MS 50-60 ile 80-

\footnotetext{
60 Meriç 2002, 53, lev. 24, K242b.

${ }^{61}$ Ladstätter 2008, 102, lev. 276, TS 25.

62 Uygun 2011, 67, lev. 29, 438-439.

63 Sackett 1992, 157, lev. 166, F2.9a.

64 Hayes 1985, 63, lev. XIV, 3.

65 Hayes 1985, 63.

${ }_{66}$ Meryem Ana Kilisesi: Beyll 1993, 26, lev. 3, 35-39; Devlet Agorası Kuyu buluntuları: Meriç 2002, 61-62, lev. 24, K 243-252; 2 nolu Yamaç Ev: Ladstätter 2005, 185, fig. 4, 28-30; Ladstätter ve Liedl 2020, 39, lev. 2, K 17-21; Vedius Gymnasiumu: Ladstätter 2008, 102-104, lev. 276-277, TS 26-41.

${ }^{6}$ Civelek 2010, 176, fig. 9, lev. 1, 5.

68 Gasperetti 2003, 143, lev. XC, 3.

${ }^{69}$ Hellström 1965, 68, lev. 35, 210.

70 Tekkök-Biçken 1996, 100, fig. 55, D11.

71 Zelle 1997, 49, fig. 9, 71, 73.

72 Uygun 2011, 67, lev. 29-30, 440-447.

73 Yener-Marksteiner 2012, 377-378, lev. 3, 22-23.

74 Unterkircher 1983, fig. 3, Samos 11.

75 Robinson 1959, 24-25, 54, lev. 61, G19, J28; Hayes 2008, 151-152, fig. 11, 303-315.

76 Sackett 1992, 221, lev. 166, F2.10a.

77 Kenrick 1985, 249, fig. 45, B351.1-2.

78 Anderson-Stojanović 1992, 51, lev. 35, 304-306.

79 Vapur 2001, 17-18, çiz. 1, 6-7.

80 Vapur 2011, 151-152, çiz. 2, 20-21.

81 Hayes 1985, 64, lev. XIV, 5-8.
} 
90 yılları arasına tarihlendirilmiştir. Hayes, formun en yaygın görülen örneği olan, altta çıkıntı oluşturan geniş kenara sahip tabakların MS 150'ye kadar devam ettiğini bildirmiştir. Ayrıca cidarın inceldiği ve dışta görülen bombeliğin düzeldiği, genellikle daha geniş çapa sahip örnekler ise MS 3. yüzyılın ortalarına kadar görülmektedir ${ }^{82}$. Geniş tarih aralığında ufak farklar ile uzun süre üretimde kalan tabak formundan Güney Stoa'da 6 adet ele geçmiştir. Bu parçalardan kat. no. 12, formun erken örneklerindendir. İçe dönük kenar, ince uçla sonlanan dudak, eğimli sığ gövde, düz dip özelliği gösteren, kenar ile gövdenin çift sıra yiv ile ayrıldığı tabak, DSB-II yapısına sahip Form 60' Hayes'in önerisiyle MS 1. yüzyılın ikinci yarısına tarihlendirilmiştir. Kat. no. 13-15 ise altta çıkıntı oluşturan geniş kenar özelliği gösteren formun yaygın örneklerindendir ve MS 2. yüzyılın ilk yarısına tarihlendirilmiştir. Kat. no. 16 ve 17 ise öncekilere benzer bir görünüme sahip fakat daha ince cidarlı ve daha geniş kenar özelliği gösterir. Bu örnekler ise MS 2. yüzyılın ikinci yarısı ile MS 3. yüzyılın ilk yarısına tarihlendirilebilir. Tralleis83, Ephesos'un çeşitli alanlarında84, Apollon Smintheios ${ }^{85}$, Metropolis ${ }^{86,}$ Labraunda $^{87}$, Troia88, Assos ${ }^{89}$, Patara ${ }^{90}$, Limyra ${ }^{91}$, Anemurium ${ }^{92}$, Samos ${ }^{93}$, Knossos ${ }^{94}$, Korinth ${ }^{95}$, Atina Agoras ${ }^{96}$, Stobi ${ }^{97}$ ve Berenice' de ${ }^{98}$ benzerleri olan Hayes Form 60, Menderes Magnesiasi'nda Gymnasium ${ }^{99}$, Theatron ${ }^{100}$ ve Hypoukaustlu Yapı' da ${ }^{101}$ da bulunmuştur.

\section{Kase}

Hayes Form 70: (Lev. 4-5, Kat. No. 18-23)

Dikey kenar, içbükey eğimli konik gövde ve halka kaide özelliği gösteren kase formudur. Yaygın kullanım gören konik gövdeli kaseler Hayes tarafından Form 70 olarak sinıflandırılarak, MS 50/75-125 yılları arasına tarihlendirilmiştir ${ }^{102}$. Tondosunda genellikle rozet bezemesi olan kaselerin erken örneklerinde dudak kenarında spiral motifi görülebilmektedir. Kat. no. 18 hamur-astar özellikleri ile özenli işçiliği dikkate alındığında bu gruba girer ve MS 1. yüzyılın sonu ile 2. yüzyılın ilk yarısına tarihlendirilebilir. Hayes Form 70 başlığ 1 altında değerlendirilebilecek tam form veren kat. no. 19, ağız-gövde parçası olarak ele geçen kat. no. 20-22 ve kaide parçası olan kat. no. 23, bozulmuş hamur-astar

\footnotetext{
82 Gassner 1997, 127; Erol 2004, 77; Hayes 2008, 39; Vapur 2013, 644.

83 Erol 2004, 75-77, lev. 95-97, 448-490; Civelek 2010, 176-177, fig. 11, 7.

84 Meryem Ana Kilisesi: Beyll 1993, 28, lev. 4, 44-50; Tetraganos Agorası Güney Kapısı: Gassner 1997, 132, lev. 43, 507-510; Devlet Agorası Kuyu buluntuları: Meriç 2002, 62, lev. 24-25, K253-269; ; 2 nolu Yamaç Ev: Ladstätter 2005, 185, fig. 4, 31-33; Ladstätter ve Liedl 2020, 40, lev. 2-3, K 27-30; Vedius Gymnasiumu: Ladstätter 2008, 104105, lev. 277, TS 42-55.

85 Akyürek 1992, 131, fig. 4, 13.

86 Güngör 2005, 47, lev. 23-25, 127-138; Ekin-Meriç 2014, 20, lev. 1, 3-4.

87 Hellström 1965, 69, lev. 35, 240.

88 Tekkök-Biçken 1996, 100, fig. 55, D13; Tekkök et al. 2001, 350, lev. 4, 26.

89 Zelle 1997, 50-51, fig. 9-10, 81-90.

90 Uygun 2011, 68-69, lev. 30-31, 452-459.

91 Yener-Marksteiner 2012, 378, lev. 3, 25.

92 Williams 1989, 19-20, fig. 7, 104-109.

93 Unterkircher 1983, 184, fig. 3, Samos 12.

94 Sackett 1992, 212, 230, lev. 156, 172, N1.11, D1.2-4; Forster 2009, 91, fig. 4.5, 38-39.

95 Slane 1990, 50, fig. 6, 94.

96 Robinson 1959, 25, lev. 61, G25; Hayes 2008, 155-157, fig. 12-13, 345-371.

97 Anderson-Stojanović 1992, 51-52, lev. 35-37, 307-317.

98 Kenrick 1985, 249-250, fig. 45, B352.1-7.

99 Vapur 2001, 20-23, çiz. 2-3, 9-18.

100 Vapur 2011, 152-153, çiz. 3, 23-28.

101 Vapur 2013, 644, çiz. 1, 9-16.

102 Hayes 1985, 66-67, lev. XV, 1.
} 
özelliği ve kaba işçiliği ile belirtilen tarihten daha geç olmalıdır. MS 3. yüzyılın ortalarına103 kadar üretimde kaldığı düşünülen kase örnekleri daha sığ ve kalın cidarlıdır. Erken örneklerde kenar bezemesi olarak sık görülen rulete karşın, bu örneklerin kenarı sade bırakılmıştır. Tralleis'104, Ephesos'un çeşitli alanlar1 ${ }^{105}$, Metropolis ${ }^{106}$, Labraunda107, Patara108, Andriake109, Limyra110, Knossos'11, Atina Agorasi112, Stobi113, Berenice ${ }^{114}$ ve Menderes Magnesiası Theatronu ${ }^{115}$ ile Hypoukaustlu Yapı'da ${ }^{116}$ bulunan Hayes Form $70^{\prime}$ in benzerleri incelendiğinde, kat. no. 19-23, kat. no. 18'den daha geç olacak şekilde, MS 2. yüzyılın ikinci yarısı ile 3. yüzyılın ilk yarısına tarihlendirilmesi mümkündür.

Hayes Form 71: (Lev. 5, Kat. No. 24)

Yuvarlak uçla sonlanan dudak, eğimli gövde özelliği gösteren kase formudur. Hayes'in Form $71^{117}$ olarak sınıflandırdığı kaselerin genel özelliği, tondo merkezinde damga ve onu çevreleyen yiv bezemesidir. Güney Stoa'da kenar-gövde parçası olarak tek örnek ele geçmiştir. Küçük boyutlu olmasına rağmen çapı ve iç yüzde tondoya dönüşün net olarak izlenebilmesi, parçanın Form 71 olarak değerlendirilebileceğini göstermektedir. Tralleis ${ }^{118}$, Ephesos 2 nolu Yamaç Ev ${ }^{119}$ ve Vedius Gymnasiumu120, Metropolis ${ }^{121}$, Assos ${ }^{122}$, Patara ${ }^{123}$, Limyra ${ }^{124}$, Knossos ${ }^{125}$, Atina Agoras1 ${ }^{126}$, Stobi ${ }^{127}$, Berenice ${ }^{128}$ ve Menderes Magnesias1 Hypoukaustlu Yapı'da ${ }^{129}$ benzerleri incelenen kat. no. 24, MS 1. yüzyılın sonu ile 2. yüzyılın ilk yarısına tarihlendirilmiştir.

\section{Tabak}

Hayes Form 80: (Lev. 5-6, Kat. No. 25-26)

Gövdeyle yiv veya içbükey profil ile birleşen geniş kenar, dışa uzantılı dudak, yuvarlak gövde ve halka kaideli tabak formudur. Hayes tarafından Form $80^{130}$ olarak

103 Robinson 1959, 54, lev. 62, J29; Vapur 2013, 645; Ekin-Meriç 2014, 21, lev. 2, 7-10.

104 Civelek 2010, 177, lev. 2, 12.

105 Meryem Ana Kilisesi: Beyll 1993, 26, lev. 3, 28-33; Tetraganos Agorası Güney Kapısı: Gassner 1997, 133, lev. 43, 514-515; Devlet Agorası Kuyu buluntuları: Meriç 2002, 62-63, lev. 26, K270-279; ; 2 nolu Yamaç Ev: Ladstätter ve Liedl 2020, 41, lev. 4, K 48-50; Vedius Gymnasiumu: Ladstätter 2008, 105-106, lev. 278, TS 58-67.

106 Güngör 2005, 46, lev. 21-23, 108-126; Ekin-Meriç 2014, 21, lev. 2, 7-10.

107 Hellström 1965, 32-33, lev. 35, 221-224.

108 Uygun 2011, 70-71, lev. 31-32, 465-476.

109 Özdilek 2018, 646-647, fig. 8-9, 4-5.

110 Yener-Marksteiner 2012, 377, lev. 3, 20-21.

111 Sackett 1992, 221, 230, lev. 166, 172, F2.15, D1.1.

112 Robinson 1959, 54, 87, lev. 62, J29, M33; Hayes 2008, 157-159, fig. 13, 377-398.

113 Anderson-Stojanović 1992, 52, lev. 38, 320-325.

114 Kenrick 1985, 253, fig. 46, B359.1-3.

115 Vapur 2011, 149-150, çiz. 2, 13-14.

116 Vapur 2013, 645, çiz. 2, 19-29.

117 Hayes 1985, 67, lev. XV, 2.

118 Civelek 2010, 178, lev. 2, 13.

119 Ladstätter ve Liedl 2020, 41-42, lev. 4, K51-53.

${ }^{120}$ Ladstätter 2008, 106, lev. 278, TS 68-73.

121 Güngör 2005, 47, lev. 25-26, 139-142.

122 Zelle 1997, fig. 10, 98-102.

123 Uygun 2011, 69-70, lev. 31, 461.

124 Yener-Marksteiner 2012, 378, lev. 3, 26.

125 Sackett 1992, 221, lev. 167, F2.16.

126 Robinson 1959, 25, lev. 62, G29-30; Hayes 2008, 159-160, fig. 13, 399-414.

127 Anderson-Stojanović 1992, 52, lev. 38, 326.

128 Kenrick 1985, 254, fig. 46, B360.1-2.

129 Vapur 2013, 645, çiz. 2, 30-33.

130 Hayes 1985, 69-70, lev. XV, 15. 
sınıflandırılan tabakların tondo merkezi basamaklandırılarak oyulmuş özellikte ve damgasızdır. Bu şekli ile metal pateraların ${ }^{131}$ taklidi gibi görünmektedir. Güney Stoa'da Form 80 olarak değerlendirilebilecek bir adet kenar-gövde (kat. no. 25) ile bir adet de kaide parçası (kat. no. 26) ele geçmiştir. Tralleis ${ }^{132}$, Ephesos Meryem Ana Kilisesi ${ }^{133}$ ve Vedius Gymnasiumu134, Patara135, Knossos'136, Korinth137, Atina Agoras1138, Berenice ${ }^{139}$ ve Menderes Magnesiası Theatron'unda ${ }^{140}$ benzerleri olan kase/çanak parçaları MS 1. yüzyılın sonu ile 2. yüzyılın ilk yarısına tarihlendirilmiştir.

\section{Çift Kulplu Kase}

Mitsopoulos-Leon H 144: (Lev. 6, Kat. No. 27-29)

Gövdeyle keskin açıyla birleşen dik kenar, kenara yerleştirilmiş çift halka kulp, derin konik gövde ve yüksek halka kaide özelliği gösteren kase formudur. Kaidenin oturma düzlemine yakın olan iç yüzünde bir ya da iki sıra derin yiv ve halka kulpların üzerinde yatay bant bulunur. Hayes'in tipolojisinde yer almayan bu kaseler nadir görülmektedir. Ephesos Bazilikası'nda141 DSB grubu içerisinde "Kulplu Sigillata" olarak tanımlanan Mitsopoulos-Leon'un H 144 örneği, Hellenistik Dönem formlarına yakın olması itibari ile MÖ 1. yüzyıl sonları ile MS 1. yüzyıl başına tarihlendirilmiştir. Labraunda'da ${ }^{142}$ bu forma ait olabilecek iki adet kaide "Çeşitli Sigillatalar" başlı̆̆ı altında değerlendirilmiştir. Tralleis'te ${ }^{143}$ de bu formun benzerleri sayılabilecek kenar-kulp parçaları ele geçmiş ve MitsopoulosLeon'un tarihlendirilmesine bağlı kalınmıştır. Ayrıca Menderes Magnesiası Hypoukoustlu Yap $1^{144}$ buluntuları arasında da bu kase formuna ait olabilecek çok sayıda parça ele geçmiştir. Ö. Vapur tarafından ayrıntılı olarak tanımlanan kaseler, DSB-II hamur-astar özelliği gösterir ve MS 1. yüzyılın ikinci yarısı ile 2. yüzyılın ilk yarısına tarihlendirilmiştir. Güney Stoa'da bu forma ait bir adet kenar-kulp (kat. no. 27), iki adet de kaide parçası (kat. no. 28-29) ele geçmiştir. Kaide parçaları Mitsopoulos-Leon'un kaide içinin kademelendirildiği H 144 örneğine uymamakla beraber Güney Stoa'da bulunan örneklerin kaide içinde yer alan tek sıra yiv ile formun sonraki dönemlerde sadeleştirilmiş olabileceği söylenebilir. Vapur'un Hypoukoustlu Yapı çalışmasında bu forma ait tam form veren $36^{145}$ numaralı örneği de içi astarlı olan kat. no. 28-29 kaidelerinin çift kulplu kase tipinin parçaları olduğunu gösterir niteliktedir. Mat kalın astara sahip olan örnekler Vapur'un önerisine uyularak MS 1. yüzyılın ikinci yarısı ile 2. yüzyılın ilk yarısına tarihlendirilmelidir.

\section{Sonuç}

Menderes Magnesiası Artemis Kutsal Alanı Güney Stoa ve mekanlarında 160 adet Doğu Sigillata B bulunmuştur. Çoğu gövde ve form tespiti yapılamayacak boyutta olan seramiklerin 29 adeti (fig. 2) DSB-I ve DSB-II olmak üzere iki alt başlık halinde incelenmiştir.

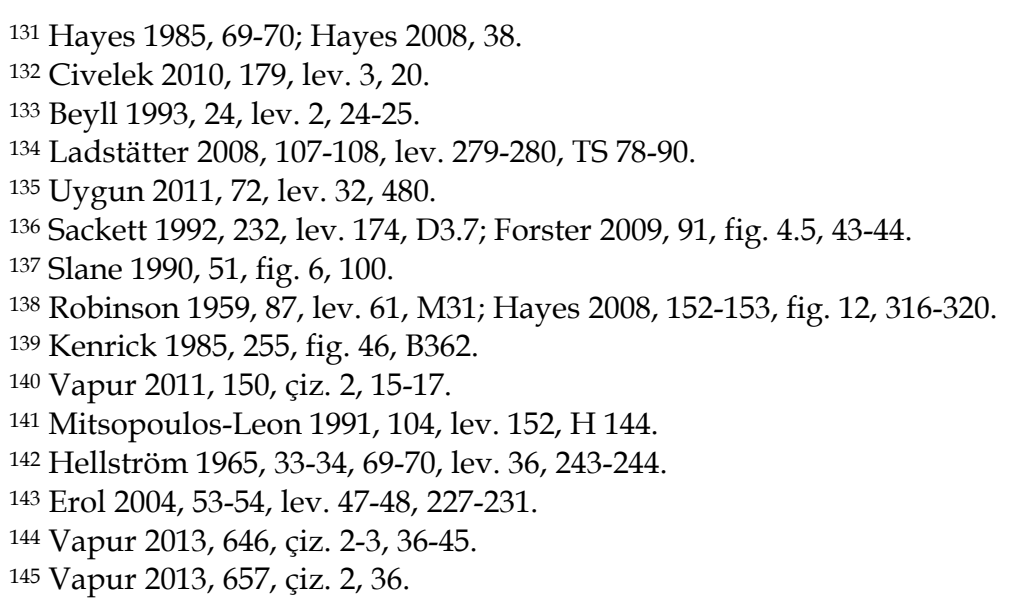


7 adetten oluşan DSB-I seramikleri Hayes Form 7, 19, 22, 26 ve 29 olmak üzere 5 farklı forma ayrılmıştır. Form 7 ve 19 tabak, Form 22, 26 ve 29 ise kaselerden oluşan seramiklerin tümünün kili katkısız olup, hamur rengi 2.5YR 6/8, astar rengi 2.5YR 4/8' dir. Grubun en erken formunu MÖ 1. yüzyılın sonu ile MS 1. yüzyılın ilk çeyreği arasına tarihlendirilen Form 22 oluştururken; en geç formunu ise MS 1. yüzyılın ortalarına tarihlendirilen Form 19 oluşturmaktadır. 22 adet parçadan oluşan DSB-II seramikleri ise Hayes Form 57, 58, 60, 70, 71, 80 ve Mitsopoulos-Leon H 144 olmak üzere 7 farklı forma ayrılmıştır. Form 57, 58, 60 ve 80 tabak; Form 70 ve 71 kase; H 144 çift kulplu kaselerden oluşan seramiklerin kili az veya yoğun mika, az kireç katkılı olup, hamur rengi 2.5YR 6/8, 5YR 6/4, astar rengi ise 2.5YR 4/8, 5/8; 10R 4/8, 5/8'dir. DSB-II'nin en erken formunu MS 1. yüzyılın ikinci yarısına tarihlendirilen Form 58 oluştururken, en geç formunu ise MS 2. yüzyılın ikinci yarısı ile 3. yüzyılın ilk yarısına tarihlendirilen Form 60 ve 70' in son örnekleri oluşturmaktadır.

Mimari süsleme açısından Erken İmparatorluk Dönemi'ne ${ }^{146}$ tarihlendirilen Güney Stoa'da bulunan seramikler 20. yüzyılın başlarında yapılan sistemsiz kazılar ve Menderes Çayı'nın düzenli olarak taşması neticesinde oldukça karışmış dolgu topraktan gelmektedir. $\mathrm{Bu}$ durum, Menderes Çayı'na yakın olan yerlerin özellikle üst tabakalarında ve geçmiş dönemlerde insan tahribatına maruz kalan Artemis Kutsal Alanı gibi sektörlerde stratigrafinin saptanabilmesini imkansız kılmaktadır. Bu nedenle yapılan anoloji, malzeme grubunun kent bazında az bilinen seramik geçmişi ve yakın kentlerle olan ilişkileri hakkında katkı sunmaktadır. Özellikle tipolojik ve kronolojik sorunu olan Mitsopoulos-Leon H 144'ün DSB-II'de de ufak form değişikliği ile devam ettiği Magnesia147 buluntuları ile gösterilmektedir. Ayrıca MS 2. yüzyılın ikinci yarısı ile 3. yüzyılın ilk yarısına tarihlendirilen yapısal farklılıklara sahip Form 60 ve 70'in son örnekleri, ilk kapsamlı kronolojik çerçevede MS 2. yüzyılın ortalarında bitiş tarihi verirken, son araştırmalar ile bu tarihin en azından MS 3. yüzyılın ortalarına kadar bölgesel anlamda da olsa uzatılması gerektiği fikrini desteklemektediritr.

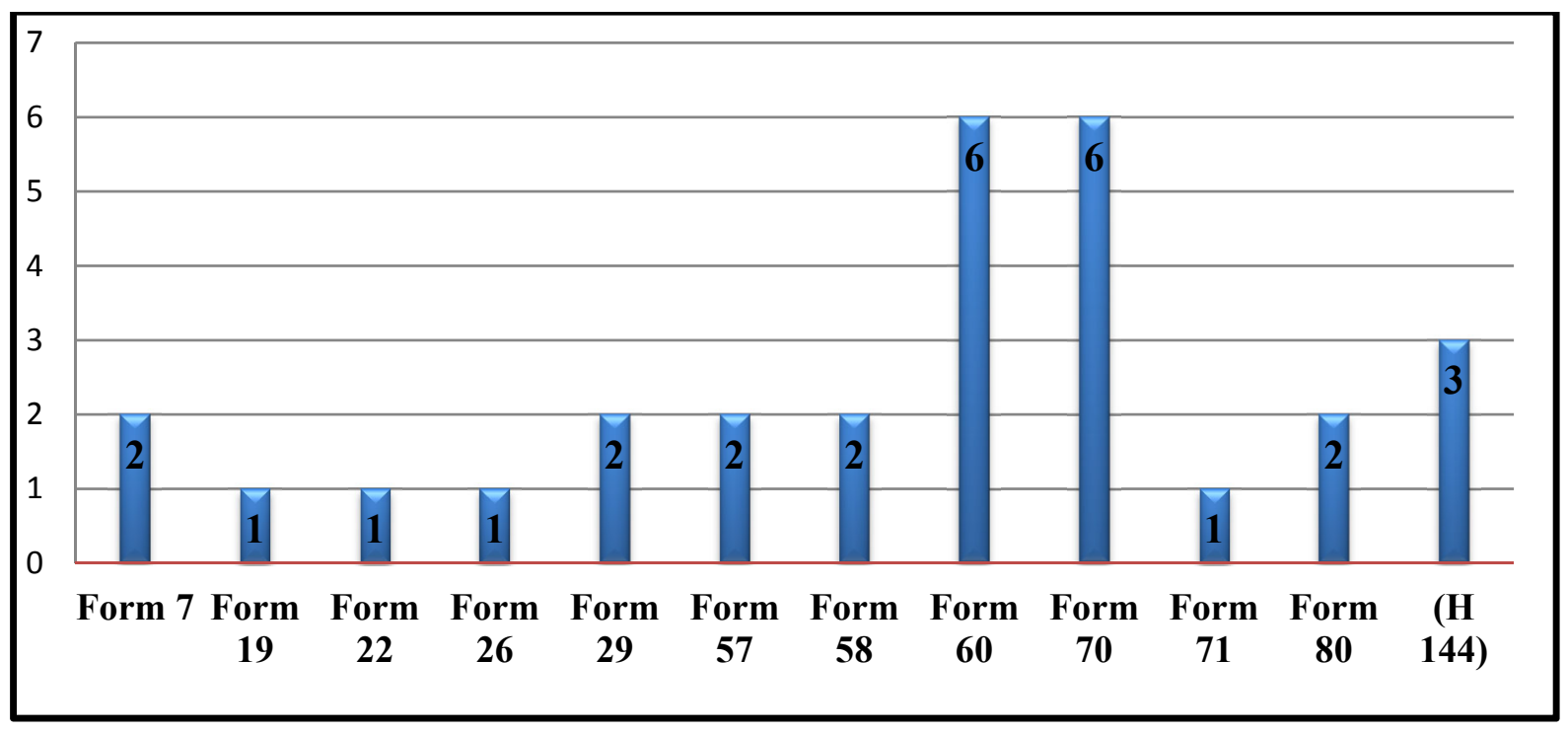

Figür 2: DSB'lerin formlara göre istatistiki dağılımı

\footnotetext{
146 Bingöl 2007, 89; Bingöl ve Oral 2009, 393-395, fig. 9; Gider 2014, 141.

147 Vapur 2013, 646, çiz. 2-3, 36-45.

148 Hayes 2008, 39-40; Ladstätter 2008, 111; Bes 2017, 243.
} 


\section{Katalog}

(Katalogda kullanılan kısaltmalar; A.Ç: Ağız Çapı, K.Ç: Kaide Çapı, Y: Yükseklik; Çizimlerde kat. no. 16-17 \%30 diğerleri \%50 oranında küçültülmüştür.)

\section{DSB-I}

Katalog No: 1

Form: Tabak, Hayes Form 7

Buluntu Yeri, Tarihi: Güney Stoa, 2000

Ölçüler: A.Ç: $14 \mathrm{~cm} \mathrm{Y:} 2.5 \mathrm{~cm}$

Hamur Rengi: 2.5YR 6/8 light red

Astar Rengi: 2.5 YR $4 / 8$ red

Benzerleri: Hayes 1985, 54-55, lev. XI, 18; Ateş 2002, 326, fig. 2, 2.

Tarih: MS 1. yüzyılın ilk yarısı

Katalog No: 2

Form: Tabak, Hayes Form 7

Buluntu Yeri, Tarihi: Güney Stoa, 2000

Ölçüler: K.Ç: $7 \mathrm{~cm}$ Y: $1.3 \mathrm{~cm}$

Hamur Rengi: 2.5YR 6/8 light red

Astar Rengi: 2.5YR 4/8 red

Benzerleri: Hayes 1985, 55, lev. XI, 17-18.

Tarih: MS 1. yüzyılın ilk yarısı

Katalog No: 3

Form: Tabak, Hayes Form 19

Buluntu Yeri, Tarihi: Güney Stoa, 2000

Ölçüler: A.Ç: $18 \mathrm{~cm} \mathrm{Y:} 2.2 \mathrm{~cm}$

Hamur Rengi: 2.5YR 6/8 light red

Astar Rengi: 2.5YR 4/8 red

Benzerleri: Hayes 1985, 57, lev. XII, 13; Erol 2004, 37, lev. 13, çiz. 66; Civelek 2010, 175, lev. 1, fig. 5, 1.

Tarih: MS 1. yüzyılın ortaları

Katalog No: 4

Form: Kase, Hayes Form 22

Buluntu Yeri, Tarihi: Güney Stoa, 1. Mekan (Trikleneum), 2006

Ölçüler: A.Ç: $14 \mathrm{~cm}$ Y: $4.6 \mathrm{~cm}$

Hamur Rengi: 2.5YR 6/8 light red

Astar Rengi: 2.5YR 4/8 red

Benzerleri: Hayes 1973, 454, lev. 86, 141.

Tarih: MÖ 1. yüzyıl sonu - MS 1. yüzyılın ilk çeyreği

Katalog No: 5

Form: Kase, Hayes Form 26

Buluntu Yeri, Tarihi: Güney Stoa, 2000

Ölçüler: K.Ç: $3 \mathrm{~cm}$ Y: $1.8 \mathrm{~cm}$

Hamur Rengi: 2.5YR 6/8 light red

Astar Rengi: 2.5YR 4/8 red

Benzerleri: Mitsopoulos-Leon 1991, 103, lev. 146, H 113; Hayes 1985, 58, lev. XII, 22; Ateş 2003, 185-186, lev. 62, 351; Hayes 2008, 148, fig. 10, 268.

Tarih: MS 1. yüzyılın ilk yarısı

Katalog No: 6

Form: Kase, Hayes Form 29

Buluntu Yeri, Tarihi: Güney Stoa, 2000

Ölçüler: A.Ç: $12 \mathrm{~cm}$ Y: $3.5 \mathrm{~cm}$

Hamur Rengi: 2.5YR 6/8 light red, az mika

Astar Rengi: 2.5YR 4/8 red

Benzerleri: Hayes 1985, 59, lev. XII, 27; Zelle 1997, 42-43, fig. 7, 38; Meriç 2002, 51-52, lev. 23, K 224.

Tarih: MS 1. yüzyılın ilk yarısı 
Katalog No: 7

Form: Kase, Hayes Form 29

Buluntu Yeri, Tarihi: Güney Stoa, 2. Mekan, 2020

Ölçüler: A.Ç: $12 \mathrm{~cm} \mathrm{Y:} 3.9 \mathrm{~cm}$

Hamur Rengi: 2.5YR 6/8 light red

Astar Rengi: 2.5YR 4/8 red

Benzerleri: Hayes 1985, 59, lev. XII, 26-27; Ateş 2002, 332, fig. 3, 19.

Tarih: MS 1. yüzyılın ilk yarısı

DSB-II

Katalog No: 8

Form: Tabak, Hayes Form 57

Buluntu Yeri, Tarihi: Güney Stoa, 1. Mekan (Trikleneum), 2006

Ölçüler: A.Ç: $7 \mathrm{~cm}$ K.Ç: $4.2 \mathrm{~cm}$ Y: $2.1 \mathrm{~cm}$

Hamur Rengi: 2.5YR 6/8 light red, az mika

Astar Rengi: 2.5YR 4/8 red

Benzerleri: Hayes 1985, 63, lev. XIV, 2; Sackett 1992, 157, lev. 166, F2.9a; Ladstätter 2008, 102, lev. 276, TS 25; Uygun 2011, 67, lev. 29, 439.

Tarih: MS 1. yüzyılın ikinci yarısı - MS 2. yüzyılın ilk çeyreği

Katalog No: 9

Form: Tabak, Hayes Form 57

Buluntu Yeri, Tarihi: Güney Stoa, 2000

Ölçüler: K.Ç: 7 cm Y: $1.5 \mathrm{~cm}$

Hamur Rengi: 2.5YR 6/8 light red

Astar Rengi: 2.5YR 4/8 red

Benzerleri: Hayes 1985, 63, lev. XIV, 2; Sackett 1992, 157, lev. 166, F2.9a.

Tarih: MS 1. yüzyılın ikinci yarısı - MS 2. yüzyılın ilk çeyreği

Katalog No: 10

Form: Tabak, Hayes Form 58

Buluntu Yeri, Tarihi: Güney Stoa, 1. Mekan (Trikleneum), 2006

Ölçüler: A.Ç: $17.6 \mathrm{~cm}$ K.Ç: $12 \mathrm{~cm}$ Y: $3.6 \mathrm{~cm}$

Hamur Rengi: 2.5YR 6/8 light red, az mika, az kireç

Astar Rengi: 2.5YR 4/8 red

Benzerleri: Hayes 1985, 63, lev. XIV, 3; Sackett 1992, 221, lev. 166, F2.10a. Beyll 1993, 26, lev. 3, 38.

Tarih: MS 1. yüzyılın ikinci yarısı

Katalog No: 11

Form: Tabak, Hayes Form 58

Buluntu Yeri, Tarihi: Güney Stoa, ön duvar, 2012

Ölçüler: A.Ç: $12 \mathrm{~cm}$ K.Ç: $5.4 \mathrm{~cm}$ Y: $3.5 \mathrm{~cm}$

Hamur Rengi: 2.5 YR 6/8 light red, yoğun mika

Astar Rengi: 2.5YR 4/8 red

Benzerleri: Hayes 1985, 63, lev. XIV, 3; Beyll 1993, 26, lev. 3, 37; Civelek 2010, 176, fig. 9, lev. 1, 5.

Tarih: MS 75 - 125

Katalog No: 12

Form: Tabak, Hayes Form 60

Buluntu Yeri, Tarihi: Güney Stoa, ön duvar, 2012

Ölçüler: A.Ç: $20 \mathrm{~cm}$ Y: $3.3 \mathrm{~cm}$

Hamur Rengi: 2.5YR 6/8 light red, az mika

Astar Rengi: 2.5YR 5/8 red

Benzerleri: Hayes 1985, 64, lev. XIV, 5; Gassner 1997, 132, lev. 43, 507; Ladstätter ve Liedl 2020, 40, lev. 2, K $27-28$.

Tarih: MS 1. yüzyılın ikinci yarısı

Katalog No: 13

Form: Tabak, Hayes Form 60

Buluntu Yeri, Tarihi: Güney Stoa, 1. Mekan (Trikleneum), 2006

Ölçüler: A.Ç: 16 cm K.Ç: $11 \mathrm{~cm}$ Y: $3.9 \mathrm{~cm}$ 
Hamur Rengi: 2.5YR 6/8 light red, yoğun mika

Astar Rengi: 2.5YR 4/8 red

Benzerleri: Hayes 1985, 64, lev. XIV, 7; Kenrick 1985, 249-250, fig. 45, 352.6; Beyll 1993, 28, lev. 4, 46; Hayes 2008, 156, fig. 12, 357; Ladstätter 2008, 104, lev. 277, TS 44.

Tarih: MS 2. yüzyılın ilk yarısı

Katalog No: 14

Form: Tabak, Hayes Form 60

Buluntu Yeri, Tarihi: Güney Stoa, 2000

Ölçüler: A.Ç: $16 \mathrm{~cm} \mathrm{Y:} 3.6 \mathrm{~cm}$

Hamur Rengi: 2.5YR 6/8 light red, az kireç

Astar Rengi: 10R 5/ 8 red

Benzerleri: Hayes 1985, 64, lev. XIV, 7; Beyll 1993, 28, lev. 4, 48; Hayes 2008, 156, fig. 12, 357; Vapur 2011, 152-153, çiz. 3, 23.

Tarih: MS 2. yüzyılın ilk yarısı

Katalog No: 15

Form: Tabak, Hayes Form 60

Buluntu Yeri, Tarihi: Güney Stoa, 2. Mekan, 2020

Ölçüler: A.Ç: $16 \mathrm{~cm}$ Y: $3.1 \mathrm{~cm}$

Hamur Rengi: 2.5YR 6/8 light red, az mika

Astar Rengi: 2.5YR 4/8 red

Benzerleri: Hayes 1985, 64, lev. XIV, 7; Beyll 1993, 28, lev. 4, 50; Vapur 2013, 644, çiz. 1, 14.

Tarih: MS 2. yüzyılın ilk yarısı

Katalog No: 16

Form: Tabak, Hayes Form 60

Buluntu Yeri, Tarihi: Güney Stoa, 4. Mekan (İmparatorlar Salonu), 2018

Ölçüler: A.Ç: $24 \mathrm{~cm}$ Y: $4.6 \mathrm{~cm}$

Hamur Rengi: 2.5YR 6/8 light red, yoğun mika

Astar Rengi: 10R 4/8 red

Benzerleri: Hayes 1985, 64, lev. XIV, 8; Beyll 1993, 28, lev. 4, 47; Uygun 2011, 68-69, lev. 31, 458.

Tarih: MS 2. yüzyılın ikinci yarısı - MS 3. yüzyılın ilk yarısı

Katalog No: 17

Form: Tabak, Hayes Form 60

Buluntu Yeri, Tarihi: Güney Stoa, 3. Mekan (Heroon) güney duvarı dışı, 2020

Ölçüler: A.Ç: $22 \mathrm{~cm} \mathrm{Y:} 3.7 \mathrm{~cm}$

Hamur Rengi: 5YR 6/4 light reddish brown, yoğun mika

Astar Rengi: 2.5YR 5/8 red

Benzerleri: Hayes 1985, 64, lev. XIV, 8; Vapur 2001, 21-23, çiz. 3, 16; Hayes 2008, 156, fig. 13, 368; Ladstätter 2008, 104, lev. 277, TS 45; Uygun 2011, 68-69, lev. 30, 454.

Tarih: MS 2. yüzyılın ikinci yarısı - MS 3. yüzyılın ilk yarısı

Katalog No: 18

Form: Kase, Hayes Form 70

Buluntu Yeri, Tarihi: Güney Stoa, 4. Mekan (İmparatorlar Salonu), 2018

Ölçüler: K.Ç: $6 \mathrm{~cm}$ Y: $4 \mathrm{~cm}$

Hamur Rengi: 2.5YR 6/8 light red

Astar Rengi: 10R 5/8 red

Benzerleri: Robinson 1959, 87, lev. 62, M33; Hayes 1985, 66-67, lev. XV, 1; Vapur 2013, 645, çiz. 2, 28-29; Ladstätter ve Liedl 2020, 41, lev. 4, K 49.

Tarih: MS 1. yüzyılın sonu - MS 2. yüzyılın ilk yarısı

Katalog No: 19

Form: Kase, Hayes Form 70

Buluntu Yeri, Tarihi: Güney Stoa, 2. Mekan, 2020

Ölçüler: A.Ç: $8.2 \mathrm{~cm} \mathrm{K.Ç:} 4 \mathrm{~cm}$ Y: $3.7 \mathrm{~cm}$

Hamur Rengi: 2.5YR 6/8 light red, az mika

Astar Rengi: 2.5YR 4/8 red 
Benzerleri: Robinson 1959, 54, lev. 62, J29; Hayes 1985, lev. XV, 1; Anderson-Stojanović 1992, 52, lev. 38, 320; Civelek 2010, 177, lev. 2, 12; Uygun 2011, 70-71, lev. 31, 465; Ekin-Meriç 2014, 21, lev. 2, 9.

Tarih: MS 2. yüzyılın ikinci yarısı - MS 3. yüzyılın ilk yarısı

Katalog No: 20

Form: Kase, Hayes Form 70

Buluntu Yeri, Tarihi: Güney Stoa, 4. Mekan (İmparatorlar Salonu), 2018

Ölçüler: A.Ç: $9 \mathrm{~cm}$ Y: $3.6 \mathrm{~cm}$

Hamur Rengi: 2.5YR 6/8 light red, yoğun mika

Astar Rengi: 10R 4/8 red

Benzerleri: Hayes 1985, lev. XV, 1; Meriç 2002, 63, lev. 26, K278.

Tarih: MS 2. yüzyılın ikinci yarısı - MS 3. yüzyılın ilk yarısı

Katalog No: 21

Form: Kase, Hayes Form 70

Buluntu Yeri, Tarihi: Güney Stoa, 4. Mekan (İmparatorlar Salonu), 2018

Ölçüler: A.Ç: $13 \mathrm{~cm} \mathrm{Y:} 2.1 \mathrm{~cm}$

Hamur Rengi: 2.5YR 6/8 light red, az mika, az kireç

Astar Rengi: 2.5YR 4/8 red

Benzerleri: Hayes 1985, lev. XV, 1; Meriç 2002, 63, lev. 26, K278.

Tarih: MS 2. yüzyılın ikinci yarısı - MS 3. yüzyılın ilk yarısı

Katalog No: 22

Form: Kase, Hayes Form 70

Buluntu Yeri, Tarihi: Güney Stoa, 4. Mekan (İmparatorlar Salonu), 2018

Ölçüler: A.Ç: $13 \mathrm{~cm} \mathrm{Y:} 2.8 \mathrm{~cm}$

Hamur Rengi: 2.5YR 6/8 light red, az kireç

Astar Rengi: 10R 5/8 red

Benzerleri: Hayes 1985, lev. XV, 1; Meriç 2002, 63, lev. 26, K278.

Tarih: MS 2. yüzyılın ikinci yarısı - MS 3. yüzyılın ilk yarısı

Katalog No: 23

Form: Kase, Hayes Form 70

Buluntu Yeri, Tarihi: Güney Stoa, 4. Mekan (İmparatorlar Salonu), 2018

Ölçüler: K.Ç: $6 \mathrm{~cm}$ Y: $3.8 \mathrm{~cm}$

Hamur Rengi: 2.5YR 6/8 light red, yoğun mika

Astar Rengi: 10R 5/8 red

Benzerleri: Robinson 1959, 54, lev. 62, J29; Hayes 1985, lev. XV, 1; Anderson-Stojanović 1992, 52, lev. 38, 322; Civelek 2010, 177, lev. 2, 12.

Tarih: MS 2. yüzyılın ikinci yarısı - MS 3. yüzyılın ilk yarısı

Katalog No: 24

Form: Kase, Hayes Form 71

Buluntu Yeri, Tarihi: Güney Stoa, 2. Mekan, 2020

Ölçüler: A.Ç: $12 \mathrm{~cm}$ Y: $3.9 \mathrm{~cm}$

Hamur Rengi: 2.5YR 6/8 light red, az mika

Astar Rengi: 10R 5/8 red

Benzerleri: Hayes 1985, 67, lev. XV, 2; Sackett 1992, 221, lev. 167, F2.16; Hayes 2008, 159, fig. 13, 402; Ladstätter 2008, 106, lev. 278, TS 68; Yener-Marksteiner 2012, 378, lev. 3, 26; Vapur 2013, 645, çiz. 2, 30.

Tarih: MS 1. yüzyılın sonu - MS 2. yüzyılın ilk yarısı

Katalog No: 25

Form: Tabak, Hayes Form 80

Buluntu Yeri, Tarihi: Güney Stoa, 4. Mekan (İmparatorlar Salonu), 2018

Ölçüler: A.Ç: $20 \mathrm{~cm}$ Y: $3.8 \mathrm{~cm}$

Hamur Rengi: 2.5YR 6/8 light red, az mika

Astar Rengi: 10R 4/ 8 red

Benzerleri: Hayes 1985, 69-70, lev. XV, 15; Kenrick 1985, 255, fig. 46, B362; Slane 1990, 51, fig. 6, 100; Sackett 1992, 232, lev. 174, D3.7; Beyll 1993, 24, lev. 2, 25; Hayes 2008, 153, fig. 12, 320; Uygun 2011, 72, lev. 32, 480.

Tarih: MS 1. yüzyılın sonu - MS 2.yüzyılın ilk yarısı 
Katalog No: 26

Form: Tabak, Hayes Form 80

Buluntu Yeri, Tarihi: Güney Stoa, 4. Mekan (İmparatorlar Salonu), 2018

Ölçüler: K.Ç: $8 \mathrm{~cm}$ Y: $2.1 \mathrm{~cm}$

Hamur Rengi: 2.5YR 6/8 light red, az mika, az kireç

Astar Rengi: 2.5YR 4/8 red

Benzerleri: Hayes 1985, 69-70, lev. XV, 15; Kenrick 1985, 255, fig. 46, B362; Slane 1990, 51, fig. 6, 100; Hayes 2008, 152, fig. 12, 317; Civelek 2010, 179, lev. 3, 20.

Tarih: MS 1. yüzyılın sonu - MS 2. yüzyılın ilk yarısı

Katalog No: 27

Form: Çift Kulplu Kase, Mitsopoulos-Leon H 144

Buluntu Yeri, Tarihi: Güney Stoa, 2000

Ölçüler: A.Ç: $14 \mathrm{~cm}$ Y: $3.5 \mathrm{~cm}$

Hamur Rengi: 2.5YR 6/8 light red, az mika

Astar Rengi: 2.5YR 5/8 red

Benzerleri: Mitsopoulos-Leon 1991, 104, lev. 152, H 144; Vapur 2013, çiz. 2, 36-37.

Tarih: MS 1. yüzyılın ikinci yarısı - MS 2. yüzyılın ilk yarısı

Katalog No: 28

Form: Çift Kulplu Kase, Mitsopoulos-Leon H 144

Buluntu Yeri, Tarihi: Güney Stoa, 4. Mekan (İmparatorlar Salonu), 2018

Ölçüler: K.Ç: $4.6 \mathrm{~cm}$ Y: $5.4 \mathrm{~cm}$

Hamur Rengi: 2.5YR 6/8 light red

Astar Rengi: 2.5YR 4/8 red

Benzerleri: Hellström 1965, 33-34, 70, lev. 36, 244; Mitsopoulos-Leon 1991, 104, lev. 152, H 144; Vapur 2013, 646, çiz. 3,44 .

Tarih: MS 1. yüzyılın ikinci yarısı - MS 2. yüzyılın ilk yarısı

Katalog No: 29

Form: Çift Kulplu Kase, Mitsopoulos-Leon H 144

Buluntu Yeri, Tarihi: Güney Stoa, Güney Propylon, 2020

Ölçüler: K.Ç: $4.8 \mathrm{~cm}$ Y: $3.3 \mathrm{~cm}$

Hamur Rengi: 2.5YR 6/8 light red, az mika

Astar Rengi: 10R 5/8 red

Benzerleri: Hellström 1965, 33-34, 69, lev. 36, 243; Mitsopoulos-Leon 1991, 104, lev. 152, H 144; Vapur 2013, 646, çiz. 3, 45 .

Tarih: MS 1. yüzyılın ikinci yarısı - MS 2. yüzyılın ilk yarısı 


\section{Bibliyografya}

Akyürek, N. E. (1992). Terra Sigillata aus dem Heiligtum des Apollon Smintheios. Asia Minor Studien, 8, 125-165.

Anderson-Stojanović, V. R. (1992). Stobi: The Hellenistic and Roman Pottery. Princeton: Princeton University Press.

Ateş, G. (2002). Die Eastern Sigillata B aus einer Frühkaiserzeitlichen Auffüllungsschicht in Aizanoi. AA, 2001, 319-332.

Ateş, G. (2003). Die Rote Feinkeramik von Aizanoi als lokaler Kulturträger [Yayımlanmamış Doktora Tezi]. Ruprecht Karls Universität.

Bes, P. (2017). Bearing the Stamp of Change: Epigraphic Stamps on Eastern Sigillata A and B. M. Flecker (Ed.), Neue Bilderwelten: zu Ikonographie und Hermeneutik Italischer Sigillata. Tübinger Archäologische Forschungen, 23, 241-273.

Bingöl, O. (2007). Magnesia on the Meander. An Archaeological Guide: The City of Artemis with the White Eyebrows. İstanbul: Homer Yayınevi.

Bingöl, O. (2020). Menderes Magnesiası. Ankara: Bilgin Kültür Sanat.

Bingöl, O. ve Oral, M. (2009). Magnesia ad Meandrum. Kazı Sonuçları Toplantısl, 30(4), 385408.

Beyll, D. (1993). Terra Sigillata aus der Marienkirche in Ephesos Erste Zwischenbilanz. Berichte und Materialen, 5, 5-45.

Civelek, A. (2010). Red Slip Ware from Tralles Excavations. Colloquium Anatolicum, IX, 169191.

Dragendorff, H. (1895). Terra Sigillata. Ein Beitrag zur Geschichte der griechischen und römischen Keramik. Bjb, 96, 18-155.

Ekin-Meriç, A. (2014). A New Deposit from a 'Banquet Hall' of the Bath-Gymnasium in Metropolis. Öjh, 83, 11-41.

Erol, D. (2004). Tralleis Kenti Kazılarında Ele Geçen Baskılı Terra Sigillata [Yayımlanmamış Doktora Tezi]. Aydın Adnan Menderes Üniversitesi.

Forster, G. (2009). Roman Knossos: The Pottery in Context [Yayımlanmamış Doktora Tezi]. The University of Birmingham.

Gasperetti, G. (2003). Osservazioni Preliminari Sulla Ceramica Romana di Iasos di Caria, Materiali dal Quartiere a sud del Teatro. C. Abadie-Reynal (Ed.), Varia Anatolica XV: Les Céramiques en Anatolie Aux Époques Hellénistiques et Romaines, Actes de la Table Ronde d'Istanbul, 23-24 Mai 1996 (ss. 141-163). Paris: De Boccard.

Gassner, V. (1997). Das Südtor der Tetraganos-Agora, Keramik und Kleinfunde. FiE, XIII/1(1). Wien: Verlag der Österreichischen Akademie der Wissenschaften. 
Gider, Z. (2014). Doric Capitals with Ionic Cymation in the Light of Examples from Caria Region. Anodos, 11/2011, 139-148.

Güngör, E. (2005). Metropolis Kenti Ada 7 İçerisindeki Konut Seramiği [Yayımlanmamış Yüksek Lisans Tezi]. Dokuz Eylül Üniversitesi.

Hayes, J. W. (1973). Roman Pottery from the South at Corinth. Hesperia, 42(4), 416-470.

Hayes, J. W. (1985). Sigillate Orientali. G. Pugliese-Carratelli (Ed.), Atlante delle Forme Ceramiche II. Ceramica Fine Romana nel Bacino Mediterraneo (Tardo Ellenismo e Primo Impero). Enciclopedia dell'arte antica classica e orientale (ss. 1-96). Roma: Istituto della Enciclopedia italiana.

Hayes, J. W. (2008). Roman Pottery Fine Ware Imports. Agora, 32. Princeton: The American School of Classical Studies at Athens.

Hellström, P. (1965). Labraunda II.1: Pottery of Classical Later Date. Terracotta Lamps and Glass, Lund: CVK Gleerup.

Kenrick, P. M. (1985). Sidi Khrebish. Excavations at Sidi Khrebish Benghazi (Berenice) III(1): The Fine Pottery. Libya Antiqua, V. Tripoli: Department of Antiquities.

Kenyon, K. M. (1957). Roman and later wares, Terra Sigillata. J.W. Crowfoot, G.M. Crowfoot ve K. M. Kenyon (Eds.), Samaria-Sebaste: The Objects from Samaria 3: Reports of the Work of the Joint Expedition in 1931-1933 and of the British Expedition in 1935, no. 3 (ss. 281-306).

Ladstätter, S. (2005). Zur Datierung des Löwenmosaiks im Hanghaus 2 von Ephesos. Synergia: Festschrift für Friesrich Krinzinger (ss. 179-186). Wien: Phoibos.

Ladstätter, S. (2008). Terra Sigillata aus den Planierschichten des Vediusgymnasiums. M. Steskal ve M. La Torre (Eds.), Das Vediusgymnasium in Ephesos, FiE, XIV/1 (ss. 97-110). Wien: Verlag der Österreichischen Akademie der Wissenschaften.

Ladstätter, S. ve Liedl, H. (2020). Die Gefäßkeramik. S. Ladstätter (Ed.), Eine Frühkaiserzeitliche Grubenverfüllung aus dem Hanghaus 2 in Ephesos. Ergänzungshefte zu den Jahresheften des Österreichischen Archäologischen Institutes, 18 (ss. 21-99). Wien: Holzhausen.

Meriç, R. (2002). Späthellenistisch-römische Keramik und Kleifunde aus einem Schachtbrunnen am Staatsmarkt in Ephesos. FiE, IX/3. Wien: Verlag der Österreichischen Akademie der Wissenschaften.

Mitsopoulos-Leon, V. (1991). Die Basilika am Staatsmarkt in Ephesos Kleifunde. 1. Teil: Keramik Hellenistischer und Römischer Zeit, FiE, IX/2(2). Wien: Verlag der Österreichischen Akademie der Wissenschaften.

Munsell Soil Color Charts (2013). Washington D.C.: U.S. Gov. Print.

Robinson, H. S. (1959). Pottery of the Roman Period: Chronology. Agora, 5. Princeton: The American School of Classical Studies at Athens. 
Rosenthal, R. (1978). The Roman and Byzantine Pottery. E. Stern (Ed.), Excavations at Tel Mevorakh (1973-1976), Part One: From the Iron Age to the Roman Period. Qedem, 9 (ss. 14-19). The Hebrew University of Jerusalem.

Sackett, L. H. (1992). Knossos from Greek City to Roman Colony, Excavations at the Unexplored Mansion II. Athens: British School of Archaeology.

Slane, K. W. (1990). The Sanctuary of Demeter and Kore. The Roman Pottery and Lamps, Corinth, XVIII/2. Princeton: The American School of Classical Studies at Athens.

Takaoğlu, T. (2006). New Lights on the Origins of Eastern Sigillata B Ware. T. Takaoğlu (Ed.), Anadolu Arkeolojisine Katkılar, 65. Yaşında Abdullah Yaylalı'ya Sunulan Yazılar (ss. 263-267). İstanbul: Hitit Color.

Tekkök-Biçken, B. (1996). The Hellenistic and Roman Pottery from Troia: Second Century BC to Sixth Century AD [Yayımlanmamış Doktora Tezi]. University of Missouri.

Tekkök, B., Wallrodt, S., Gündem, C. Y. ve Rose, C. B. (2001). Two Roman Wells in the Lower City of Ilion. Quadrats C29 and w28. Studia Troica, 11, 343-382.

Tekocak, M. (2019). Stratonikeia Kazılarında Bulunan Kırmızı Astarlı Seramikler. B. Söğüt (Ed.), Stratonikeia Çalı̧̧malarn 4. Mimari, Heykel ve Küçük Buluntu Araştırmaları (ss. 85-123). İstanbul: Ege Yayınları.

Unterkircher, E. (1983). Terra Sigillata aus dem Heraion von Samos. AM, 98, 173-214.

Uygun, Ç. (2011). Patara IV.2: Tepecik Kırmızı Astarlı Seramikleri (İ.Ö. 2. YY - İ.S. 4. YY). İstanbul: Ege Yayınları.

Vapur, Ö. (2001). Magnesia ad Maeandrum Gymnasion'u Roma Dönemi Seramikler [Yayımlanmamış Yüksek Lisans Tezi]. Ankara Üniversitesi.

Vapur, Ö. (2011). Menderes Magnesiası Theatron Kazıs1 Seramik Buluntuları. Anadolu/Anatolia, 37, 143-193.

Vapur, Ö. (2013). Menderes Magnesiası Hypokaustlu Yapı Kazılarında Ele Geçen İthal Kaliteli Seramikler. G. Kökdemir (Ed.), Orhan Bingöl 67. Yaş Armağanı (ss. 641-666). Ankara: Bilgin Kültür Sanat.

Williams, C. (1989). Anemurium: The Roman and Early Byzantine Pottery. Toronto: Pontificial Institute of Mediaeval Studies.

Yener-Marksteiner, B. (2012). Frühkaiserzeitliche Sigillata der Weststadtgrabung in Limyra 2002-2003. M. Seyer (Ed.), 40 Jahre Grabung Limyra Akten des internationalen Symposions Wien, 3-5 December 2009 (ss. 371-386). Wien: Österreichisches Archäologisches Institut.

Yıldız, V. (2016). Akhisar Arkeoloji Müzesi'nde Bulunan Bir Grup Roma Seramiği. Manisa Celal Bayar Üniversitesi Sosyal Bilimler Dergisi, 14(3), 252-273.

Yıldız, V. (2019a). Alanya Arkeoloji Müzesi'nde Bulunan Doğu Sigillataları A, B ve C Grubu Seramikleri. Dicle Üniversitesi Sosyal Bilimler Enstitüsü Dergisi, 23, 108-127. 
Yıldız, V. (2019b). Soli Pompeiopolis Sütunlu Caddesi'nde Bulunan Doğu Sigillatası D Grubu Seramikleri. Selçuk Üniversitesi Edebiyat Fakültesi Dergisi, 42, 245-274.

Zabehlicky-Scheffenegger, S. (2003). C. Sentius and His Commercial Connections. C. AbadieReynal (Ed.), Varia Anatolica XV: Les Céramiques en Anatolie Aux Époques Hellénistiques et Romaines, Actes de la Table Ronde d'Istanbul, 23-24 Mai 1996 (ss. 117-119). Paris: De Boccard.

Zahn, R. (1904). Thongeschirr. T. Wiegand ve H. Schrader (Eds.), Priene, Ergebnisse der Ausgrabungen und Untersuchungen in den Jahren 1895-1898 (ss. 394-468). Berlin: G. Reimer.

Zelle, M. (1997). Die Terra Sigillata aus der Westtor-Nekropole in Assos. Asia Minor Studien, 27. Bonn: Verlag Dr. Rudolf Habelt. 


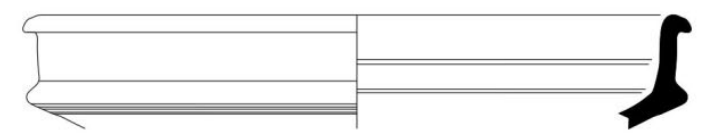

1

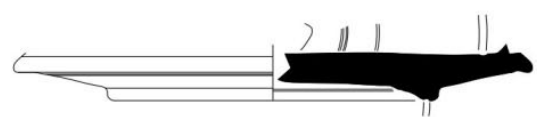

2

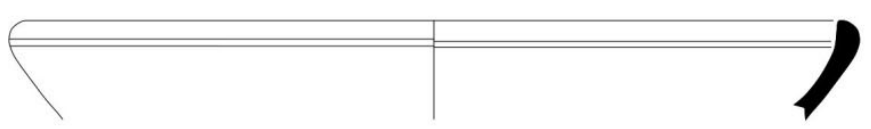

3
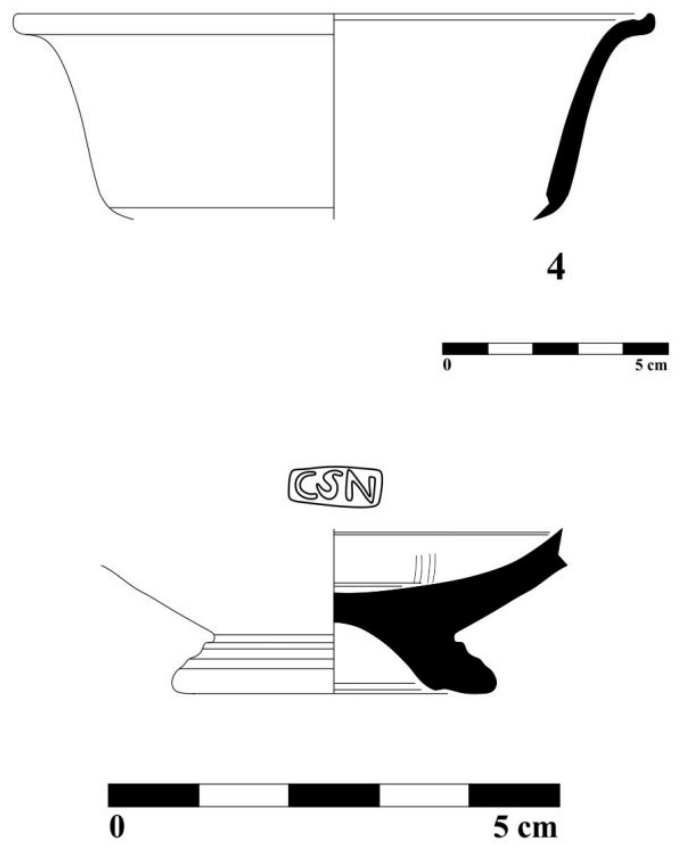

5

\section{Levha 1}




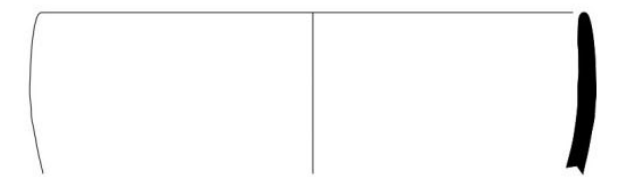

6

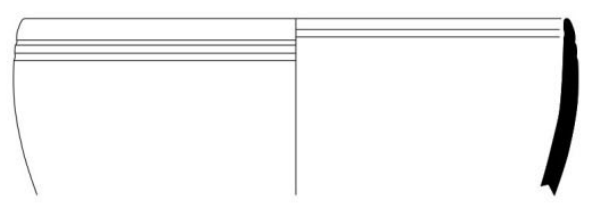

7



8

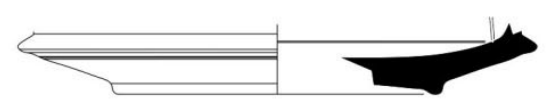

9

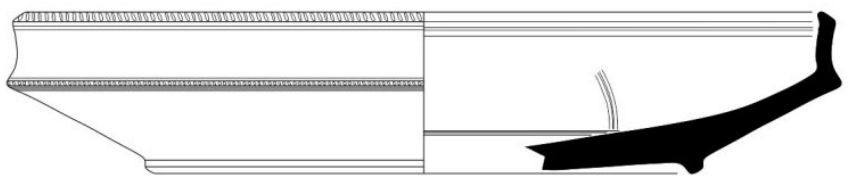

10
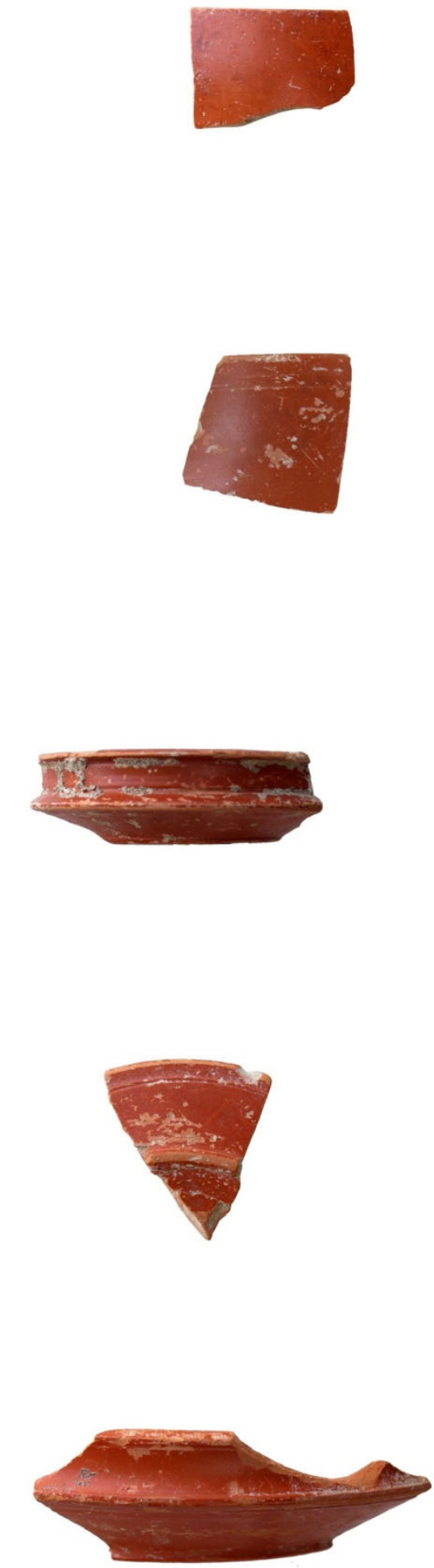

0
$5 \mathrm{~cm}$

Levha 2 


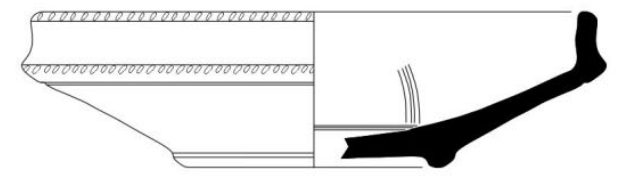

11
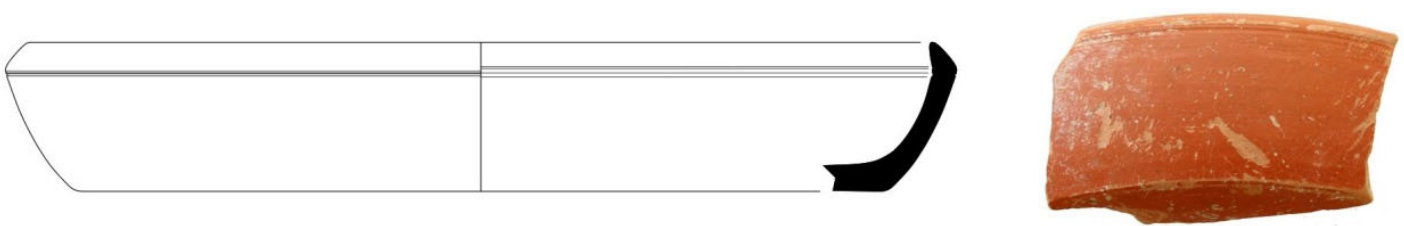

12
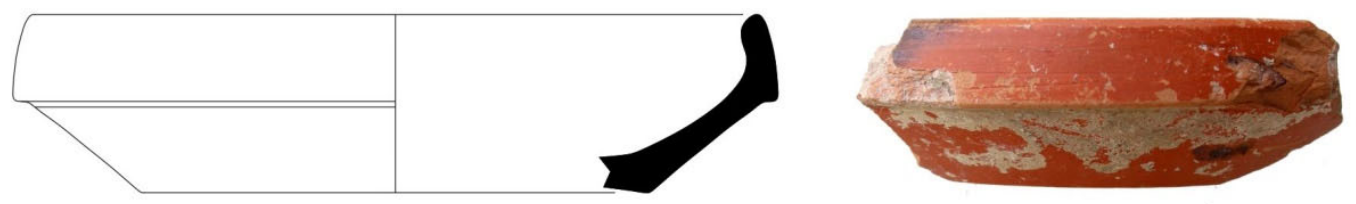

13

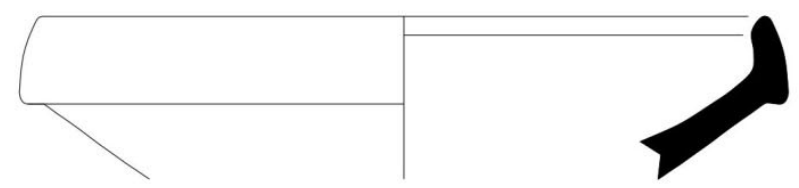

14
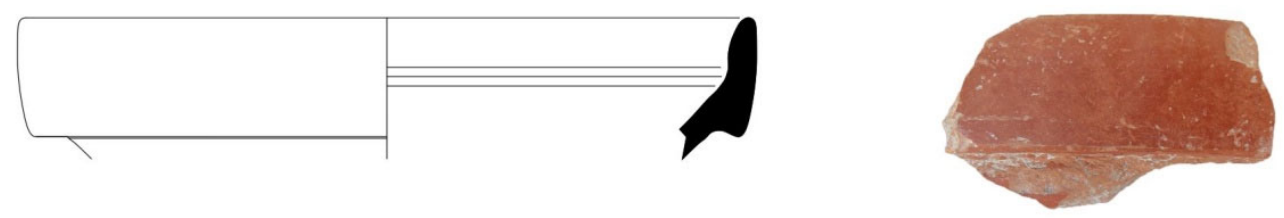

15

$5 \mathrm{~cm}$

Levha 3 


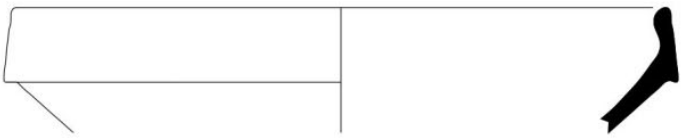

16

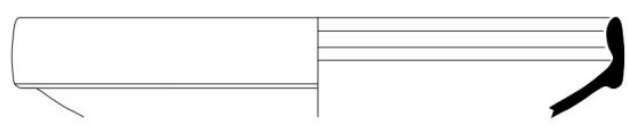

17
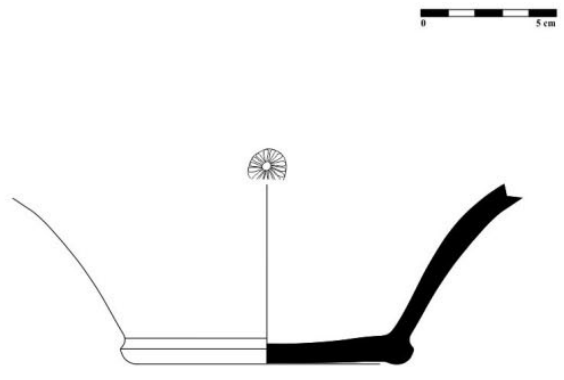

18

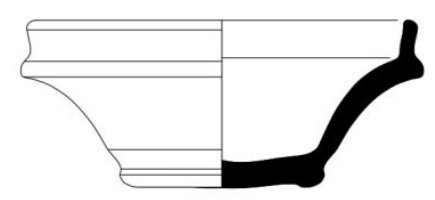

19

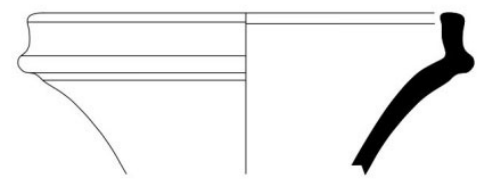

20

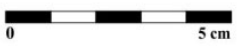

Levha 4
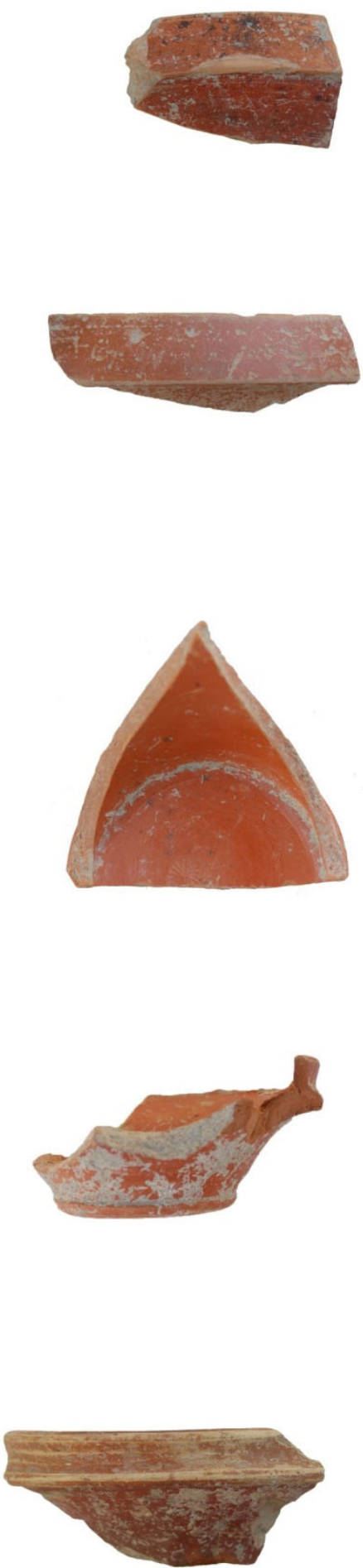

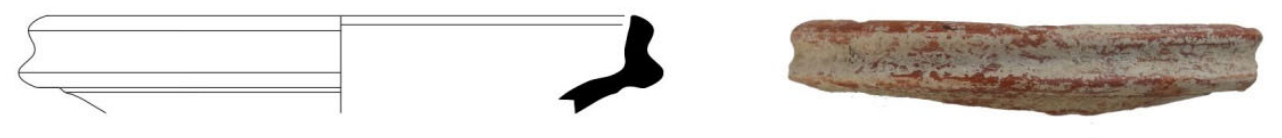

21
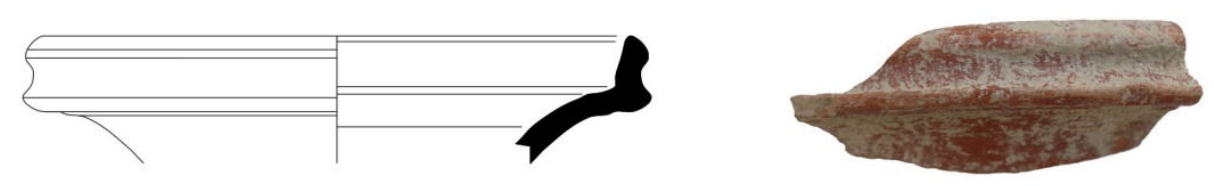

22

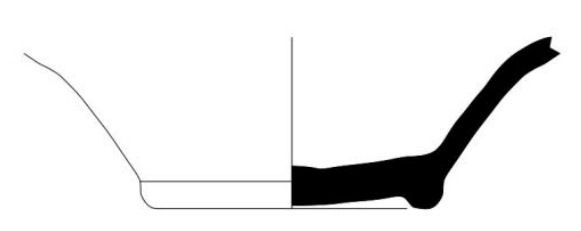

23
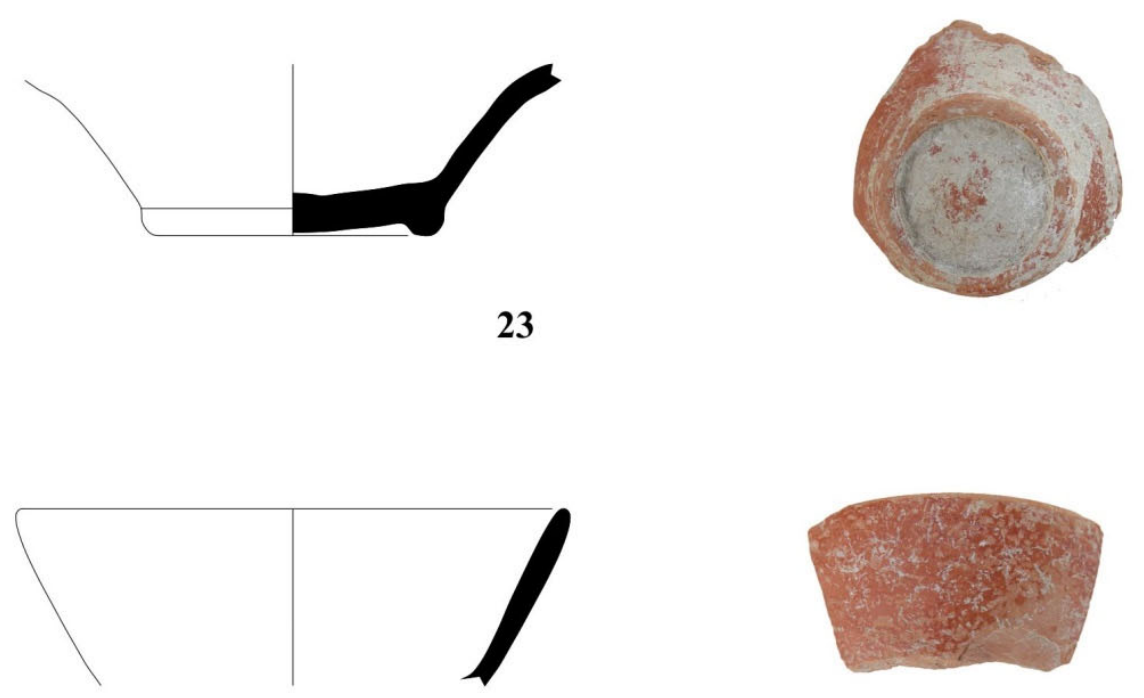

24
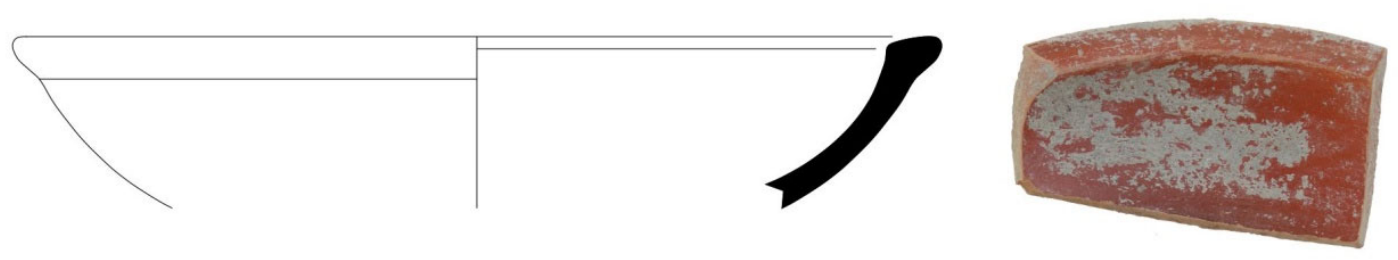

25

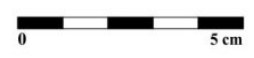

Levha 5 

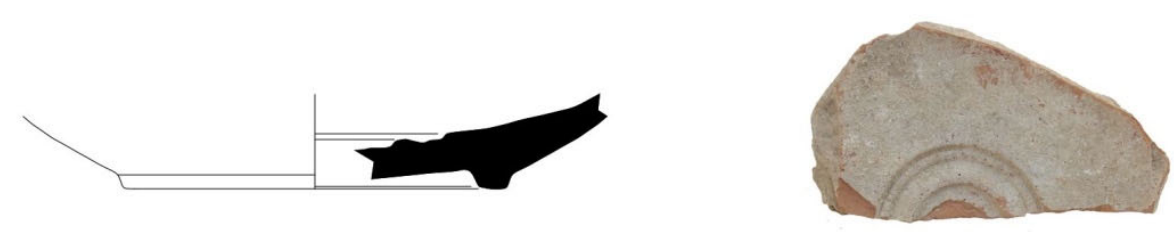

26
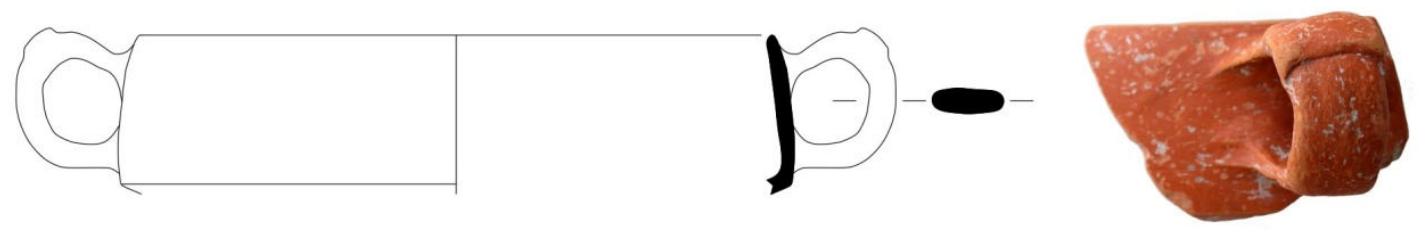

27
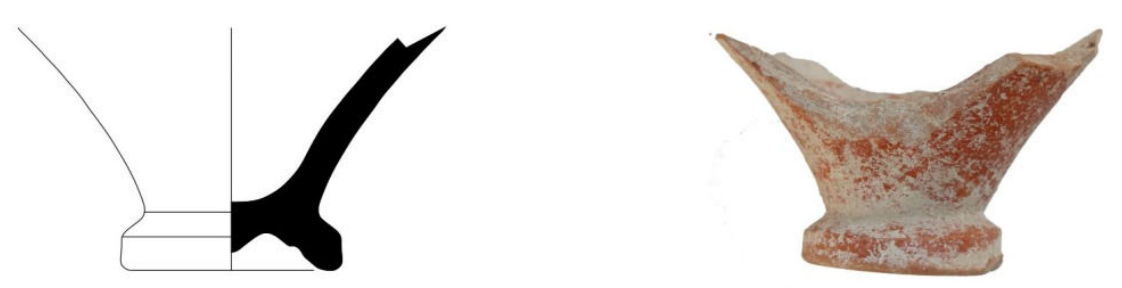

28
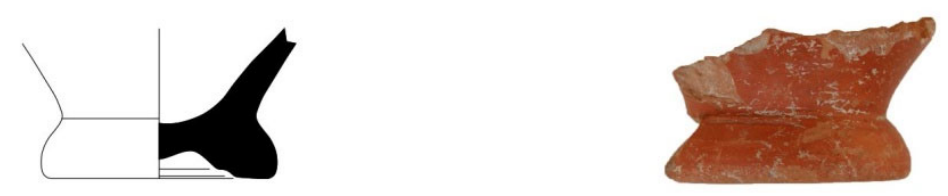

29

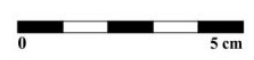

Levha 6 